\title{
ON DIABETIC ACIDOSIS
}

\section{A Detailed Study of Electrolyte Balances Following the Withdrawal and Reestablishment of Insulin Therapy}

By DANA W. ATCHLEY, ROBERT F. LOEB, DICKINSON W. RICHARDS, JR.,
ETHEL M. BENEDICT AND MARY E. DRISCOLL

(From the Department of Medicine, College of Physicians and Surgeons of Columbia University, and the Presbyterian Hospital, New York City)

(Received for publication October 17, 1932)

\section{INTRODUCTION}

In 1923, Gamble, Ross and Tisdall (1) made an important advance in the field of metabolic research by developing a method for the comprehensive analysis of the excretion of body electrolytes and water. They applied this method to the study of the acidosis occurring in starving epileptic children and were able to demonstrate the fundamental significance of mass movements of inorganic base and tissue fluids in this condition. With the addition of the measurement of electrolyte intake, this procedure has since been utilized in a number of similar problems. More recently Gamble et al. (2), Følling (3), and others have made studies of the acidosis resulting from the ingestion of $\mathrm{CaCl}_{2}$ and $\mathrm{NH}_{4} \mathrm{Cl}$. Under these circumstances, also, many alterations were noted, identical with those occurring in the acidosis of starvation.

The state of diabetic acidosis, which presents a more complex picture than do these other types of acidosis, has been described by many observers and a number of its physiological and chemical disturbances are well known. However, there has been no analysis which has successfully differentiated the phenemona due to a disturbance of carbohydrate metabolism from those due to ketogenic acidosis. When patients present themselves for treatment, the acidosis is usually so far advanced that there is little, if any, opportunity to follow the chain of events leading up to it. Furthermore, the need for therapy in these patients is so urgent that it is impossible to institute the procedures required for a complete balance study. Consequently, only fragmentary information has been gained about the response of the body to the appearance of acidosis or the process of recovery from it. For these reasons, we have studied in two cases of diabetes mellitus ${ }^{1}$ the nature and order of changes in water

1 This work was carried out on volunteers who had the nature of the experiments fully explained to them, and who received financial remuneration for their services. 
and electrolyte balances resulting from the abrupt withdrawal of insulin and also the steps taking place in recovery, when insulin is again instituted.

\section{METHODS}

The analytic methods employed in this paper have, with few exceptions, been described in previous papers (4) (5). Serum $\mathrm{pH}$ was calculated by the use of the graphic charts of Van Slyke and Sendroy (6), from the values of serum $\mathrm{CO}_{2}$ content, whole blood $\mathrm{CO}_{2}$ content, oxygen content and oxygen capacity of whole blood, and the $\mathrm{CO}_{2}$ dissociation curve of oxygenated whole blood. The technique employed in handling the blood was essentially that described by Austin, Cullen, et al. (7), with minor modifications; the latter have been described in detail in previous communications (8) (9).

\section{EXPERIMENTAL}

\section{Patient T. M., Number 239113}

This patient was a white boy of nineteen who developed diabetes at the age of twelve and who had been cared for in the wards and diabetic clinic of the Presbyterian Hospital since the onset of his disease. His diabetes was always severe, he had been through two serious attacks of acidosis, and required between 60 and 80 units of insulin daily in order to remain approximately sugar-free. In spite of this he was a well developed, active, normal youth. He was admitted to the Research Service on January 2, 1931 for this study. Nothing abnormal was found on physical examination. His blood pressure was 119/70. Routine blood counts were normal. His urine, except for the presence of glucose, was normal. His basal metabolic rate was \pm 0 per cent and his fasting respiratory quotient was $\mathbf{0 . 7 6}$.

The patient remained in bed except for four hours a day, when he was allowed to sit in a chair. He was given a diet containing 125 grams of carbohydrate, 75 grams of protein and 140 grams of fat, with a constant fluid intake. During the course of the experiment he ate identical meals each day. Every five days, when a fresh supply of food was procured, an analysis of a duplicate day's diet was made for water, total nitrogen, calcium, total inorganic base, potassium, phosphorus and chloride. Sodium and magnesium were determined together, by difference. Complete twenty-four hour urine specimens were analyzed daily for $\mathrm{NH}_{3}, \mathrm{Ca}$, $\mathrm{K}$, total inorganic base, $\mathrm{Cl}, \mathrm{P}$, inorganic $\mathrm{SO}_{4}$, total nitrogen, creatinine, ketones and sugar. The $\mathrm{pH}$ and titratable acid were also determined daily. All stools were saved, were collected in three-day, four-day or fiveday specimens, and these were analyzed for $\mathrm{Ca}, \mathrm{K}$, total inorganic base, $\mathrm{P}, \mathrm{Cl}$ and total $\mathrm{N}$. The patient received 45 units of insulin before breakfast, 35 units before supper and 10 units at midnight and remained essentially sugar-free. 
TABLE 1

Total balance data obtained on the patient T.M.

\begin{tabular}{|c|c|c|c|c|c|c|c|c|c|c|c|c|c|c|c|c|c|c|c|c|c|c|c|c|c|c|c|c|c|c|c|c|c|c|c|}
\hline \multirow[b]{2}{*}{ äّ } & \multirow[b]{2}{*}{$\begin{array}{l}\text { 量 } \\
\text { 鄫 }\end{array}$} & \multirow[b]{2}{*}{ 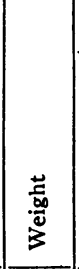 } & \multicolumn{15}{|c|}{ Urine } & \multicolumn{8}{|c|}{ Stool } & \multicolumn{9}{|c|}{ Intake } & \multirow[b]{2}{*}{$i$} \\
\hline & & & $\begin{array}{l}\stackrel{0}{0} \\
\stackrel{0}{0}\end{array}$ & 吾 & 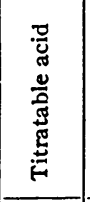 & 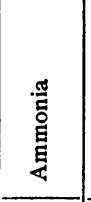 & 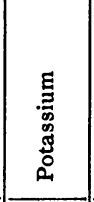 & 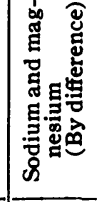 & 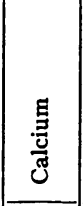 & 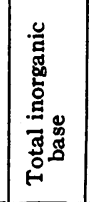 & 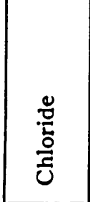 & 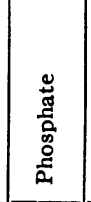 & 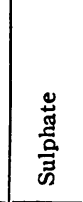 & 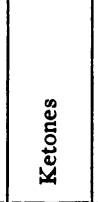 & 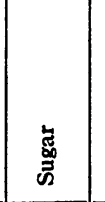 & 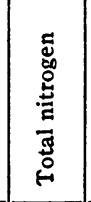 & 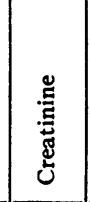 & 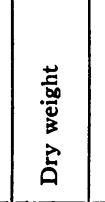 & 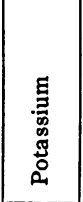 & 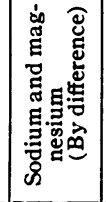 & 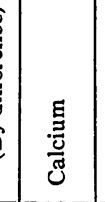 & 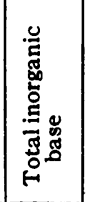 & 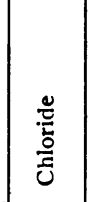 & 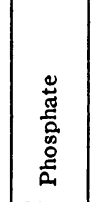 & 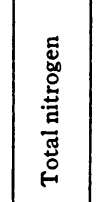 & 总 & 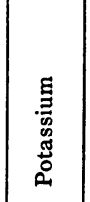 & 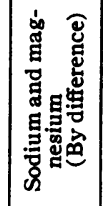 & $\frac{E}{\frac{E}{\tilde{c}}}$ & 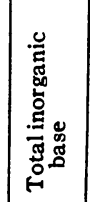 & 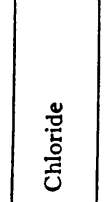 & 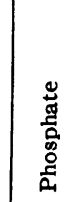 & 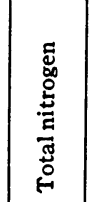 & 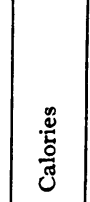 & \\
\hline January & units & $k g m$. & $c c$ & & m.eq. & m.eq. & m.eq. & m.eq. & m.eq. & m.eq. & \begin{tabular}{|l} 
m.eq. \\
\end{tabular} & m.eq. & m.eq. & grams & grams & grams & grams & $s \mid$ grams & m.eq. & m.eq. & m.eq. & m.eq. & m.eq. & m.eq. & grams & $c c$. & m.eq. & m.eq. & m.eq. & m.eq. & m.eq. & m.eq. & grams & & \\
\hline $12-13$ & 88 & 59.1 & 1010 & \begin{tabular}{|l|} 
\\
5.7
\end{tabular} & 35.2 & 42.8 & 41.3 & 61.4 & 17.3 & 120 & 44.9 & 31.8 & 45.2 & 0.07 & 3.0 & 11.3 & 1.94 & 9.6 & 3.86 & 4.6 & 16.0 & 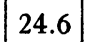 & \begin{tabular}{|l|} 
\\
\end{tabular} & 5.6 & 0.56 & 2759 & 68.8 & $\mid 117.2$ & 51.8 & 238 & 99.7 & 81.3 & 13.3 & 2106 & 6 Foreperiod \\
\hline $13-14$ & 85 & 59.2 & 1095 & 6.4 & 21.5 & 37.0 & 55.5 & \begin{tabular}{|l|} 
\\
\end{tabular} & 19.4 & 164 & 76.2 & 38.1 & 45.7 & 0.12 & + & 11.7 & 2.15 & 9.6 & 3.86 & 4.6 & 16.0 & |24.6 & \begin{tabular}{|l|}
0.3 \\
\end{tabular} & 5.6 & 0.56 & $\mid 2739$ & 68.8 & 117.2 & 51.8 & 238 & 99.7 & 81.3 & 13.3 & 2069 & \\
\hline $14-15$ & 85 & 59.0 & 1200 & 6.2 & 28.2 & 43.0 & 57.7 & \begin{tabular}{|l|}
92.7 \\
\end{tabular} & 20.6 & $\mid 171$ & 95.3 & 39.9 & 49.5 & 0.11 & $0 . \dot{0}$ & 12.2 & 2.10 & 9.6 & 3.86 & 4.6 & 16.0 & \begin{tabular}{|l|}
$\mid 24.6$ \\
\end{tabular} & 0.3 & 5.6 & 0.56 & 2739 & 68.8 & 117.2 & $\mid 51.8$ & 238 & 99.7 & 81.3 & 13.3 & 2069 & \\
\hline $15-16$ & 85 & 59.0 & 1365 & 6.3 & 28.5 & 41.2 & 62.7 & 110.7 & 21.6 & 195 & 103.0 & 48.4 & 52.5 & 0.16 & + & 11.9 & 2.07 & 9.6 & 3.86 & 4.6 & 16.0 & 24.6 & 0.3 & 5.6 & 0.56 & 2739 & 68.8 & 117.2 & 51.8 & 238 & 99.7 & 81.3 & 13.3 & $2069 \mid$ & \\
\hline $16-17$ & 85 & \begin{tabular}{|l|} 
\\
\end{tabular} & 1560 & 6.1 & 32.5 & 44.0 & 63.6 & 100.7 & 22.7 & 187 & 97.3 & 40.8 & 50.8 & 0.20 & + & 12.8 & 2.11 & 9.6 & 3.86 & 4.6 & 16.0 & 24.6 & 0.3 & 5.6 & 0.56 & 2739 & 68.8 & 117.2 & 51.8 & \begin{tabular}{|l|}
238 \\
\end{tabular} & 99.7 & 81.3 & 13.3 & 2069 & \\
\hline $17-18$ & 85 & 59.1 & 1105 & 6.0 & $\mid \begin{array}{l}31.7 \\
\end{array}$ & 43.7 & 59.6 & $\begin{array}{r}63.7 \\
\end{array}$ & 19.7 & \begin{tabular}{|l|l|} 
& 143 \\
\end{tabular} & 72.3 & 36.8 & 49.9 & 0.12 & 0.0 & 12.8 & 2.11 & 18.7 & $\mid \begin{array}{l}5.58 \\
\end{array}$ & 11.1 & 32.8 & 49.5 & 0.5 & \begin{tabular}{|l|l|}
13.3 \\
\end{tabular} & 1.07 & 2765 & 69.3 & 121.7 & 49.7 & 241 & 100.3 & 67.4 & 13.1 & & \\
\hline $18-19$ & 85 & 58.8 & 1210 & 6.1 & 29.6 & 38.0 & 51.5 & 80.4 & 20.1 & \begin{tabular}{|l|l|} 
& 152 \\
\end{tabular} & 73.6 & 35.8 & 42.4 & 0.14 & 0.0 & 11.4 & 2.16 & 18.7 & $\mid \begin{array}{l}0.00 \\
\end{array}$ & 11.1 & 32.8 & 49.5 & 0.5 & $\mid \begin{array}{l}\mid \\
13.3\end{array}$ & 1.07 & 2765 & 69.3 & 121.7 & 49.7 & \begin{tabular}{|l|l|}
241 \\
241
\end{tabular} & 100.3 & 67.4 & $\begin{array}{l}10.1 \\
13.1\end{array} \mid$ & 2069 & \\
\hline 19-20 & 85 & 59.0 & 830 & \begin{tabular}{|l|} 
\\
\end{tabular} & 26.0 & 38.4 & 53.7 & 81.2 & 20.1 & 155 & 70.8 & 33.2 & 44.9 & 0.13 & 0.0 & 11.2 & 1.98 & 18.7 & 5.58 & 11.1 & 32.8 & 49.5 & 0.5 & 13.3 & 1.07 & 2715 & 69.3 & 121.7 & 49.7 & 241 & & 67.4 & 13.1 & 2069 & \\
\hline $20-21$ & 85 & 59.0 & 1450 & \begin{tabular}{|l|}
6.4 \\
\end{tabular} & 22.4 & 36.1 & 51.9 & 118.4 & 21.7 & \begin{tabular}{|l|l|}
192 \\
\end{tabular} & 94.5 & 44.5 & 41.4 & 0.14 & 0.0 & 11.5 & 2.13 & 18.7 & 5.58 & 11.1 & 32.8 & 49.5 & 0.5 & $\mid \begin{array}{l}13.3 \\
\end{array}$ & 1.07 & 2765 & 69.3 & 121.7 & 49.7 & 241 & & 67.4 & 13.1 & 2069 & \\
\hline $21-22$ & 85 & 59.0 & $\mid 1305$ & $\mid$\begin{tabular}{|l|}
$\mid$ \\
$\mid$
\end{tabular} & 25.8 & 34.2 & 67.7 & 115.4 & \begin{tabular}{|l|}
25.9 \\
\end{tabular} & 209 & $\mid 115.6$ & 38.7 & 42.9 & 0.13 & \pm & 11.5 & 2.08 & 18.7 & 5.58 & 11.1 & 32.8 & 49.5 & 0.5 & 13.3 & 1.07 & 2765 & 69.3 & 121.7 & 49.7 & 241 & 100.3 & 67.4 & 13.1 & $|2069|$ & \\
\hline $22-23$ & 85 & 58.8 & 1080 & $|5.8|$ & 35.4 & 41.7 & 64.7 & \begin{tabular}{|l|}
67.5 \\
\end{tabular} & \begin{tabular}{|l|l|} 
& 19.8
\end{tabular} & $\mid 152$ & 77.8 & 36.9 & 45.7 & 0.17 & 0.0 & $\mid 11.6$ & 2.00 & 18.7 & \begin{tabular}{|l|} 
\\
\end{tabular} & 11.1 & 32.8 & 49.5 & 0.5 & $\mid 13.3$ & 1.07 & 2746 & 66.4 & $\mid 114.6$ & 44.3 & 225 & 99.1 & 73.2 & 12.5 & 2069 & \\
\hline $23-24$ & 85 & 58.8 & 1295 & \begin{tabular}{|l|}
$\mid 6.3$ \\
\end{tabular} & 26.7 & 32.8 & 67.8 & 90.0 & 19.2 & 177 & 69.4 & 42.7 & 45.1 & 0.12 & 0.0 & 12.1 & 2.09 & 15.8 & 4.24 & 10.4 & 39.8 & 54.4 & 0.9 & $\mid 14.0$ & 0.84 & 2746 & 66.4 & $\mid 114.6$ & 44.3 & 225 & 99.1 & 73.2 & 12.5 & 2069 & \\
\hline $24-25$ & 0 & 58.0 & 2245 & \begin{tabular}{|l|} 
\\
\end{tabular} & 46.3 & 47.7 & 138.5 & 176.3 & 31.2 & 346 & 149.4 & 72.6 & \begin{tabular}{|l|}
69.7 \\
\end{tabular} & 3.50 & $\mid 116.0$ & 17.7 & 2.82 & 15.8 & 4.24 & 10.4 & 39.8 & 54.4 & 0.9 & 14.0 & 0.84 & 2746 & 66.4 & $\mid 114.6$ & $\mid 44.3$ & 225 & 99.1 & 73.2 & $\mid 12.5$ & 2069 & \\
\hline & 0 & & 2545 & \begin{tabular}{|l|} 
\\
\end{tabular} & 90.5 & 117.7 & 129.0 & 153.1 & & 326 & 117.8 & 58.2 & 77.4 & 14.40 & 163.0 & 19.9 & 2.47 & & & 10.4 & 39.8 & 54.4 & \begin{tabular}{|l|}
0.9 \\
\end{tabular} & 14.0 & 0.84 & 2746 & 66.4 & 114.6 & 44.3 & & 99.1 & & 12.5 & 2069 & \\
\hline $26-27$ & 0 & $\mid 55.2$ & $\mid 2735$ & $|5.4|$ & 105.2 & 183.8 & $\mid 152.1$ & 162.1 & \begin{tabular}{|l|}
58.8 \\
\end{tabular} & 373 & $\mid 103.8$ & 61.8 & \begin{tabular}{|l|}
80.9 \\
\end{tabular} & 21.90 & $\mid 171.0$ & 18.1 & 2.65 & 15.8 & 4.24 & 10.4 & 39.8 & 54.4 & \begin{tabular}{|l|}
0.9 \\
\end{tabular} & $\mid 14.0$ & 0.84 & 2746 & 66.4 & 114.6 & 44.3 & 225 & 99.1 & 73.2 & 12.5 & 2069 & \\
\hline $27-28$ & 90 & 54.2 & $|2960|$ & \begin{tabular}{|l|}
5.4 \\
\end{tabular} & 141.1 & 227.0 & 187.6 & 203.8 & 80.6 & 472 & 151.5 & 84.8 & 74.8 & 31.20 & $\mid 148.0$ & 19.0 & 2.21 & 15.8 & 4.24 & 10.4 & 39.8 & 54.4 & 0.9 & 14.0 & 0.84 & 2969 & 62.4 & 178.4 & 41.0 & 282 & 187.3 & 60.9 & 8.1 & 1379 & \\
\hline & 125 & 56.2 & \begin{tabular}{|l|}
$\mid 375$ \\
\end{tabular} & $|6.1|$ & 10.3 & 69.9 & 6.0 & 1.4 & & 27 & & 10.6 & & & 0 & 5.9 & & & & 12.4 & 48.5 & 66.3 & \begin{tabular}{|l|} 
\\
\end{tabular} & $\mid 16.8$ & 0.85 & 2788 & 70.8 & $\mid 119.2$ & \begin{tabular}{|l|}
$\mid 46.8$ \\
\end{tabular} & 237 & 100.0 & 74.9 & 12.8 & $\mid 2073$ & Recovery period I \\
\hline $29-30$ & 85 & 57.0 & 1180 & 6.0 & 28.8 & 169.8 & 3.5 & 9.1 & 49 & 62 & 96.2 & 33.2 & 78 & & & 15.9 & 3.28 & 17.5 & & 12.4 & 48.5 & 66.3 & 1.5 & 16.8 & 0.85 & 2788 & 70.8 & 119.2 & 46.8 & 237 & & & 12.8 & 2073 & \\
\hline $30-31$ & 85 & 57.2 & \begin{tabular}{|l|}
630 \\
\end{tabular} & 6.0 & 21.5 & 90.9 & 0.8 & 7.7 & 22.5 & 31 & 49.4 & 33.2 & 37.4 & 0.30 & 0.0 & $\mid 10.8$ & 1.96 & 17.5 & 5.37 & 12.4 & 48.5 & 66.3 & 1.5 & 16.8 & 0.85 & 2788 & 70.8 & $\mid 118.2$ & $\mid 46.8$ & 237 & 100.0 & 74.9 & 12.8 & 2069 & \\
\hline $31-1$ & 85 & 57.3 & $\mid 1015$ & 6.2 & 23.9 & 65.5 & 13.9 & 94.6 & 22.5 & 131 & 92.8 & 32.1 & 41.2 & 0.02 & + & 12.4 & 2.03 & 17.5 & 5.37 & 12.4 & 48.5 & 66.3 & 1.5 & 16.8 & 0.85 & 2788 & 70.8 & 118.2 & 46.8 & 237 & 100.0 & 74.9 & 12.8 & 2069 & \\
\hline Februar & & & & & & & & & & & & & & & & & & & & & & & & & & & & & & & & & & & \\
\hline te & 85 & 57.4 & 1900 & 7.1 & 7.3 & 39.5 & 16.2 & 216.8 & 20.0 & 253 & $|154.0|$ & 36.7 & 37.9 & 0.25 & 0.0 & $\mid 11.8$ & 2.11 & 17.5 & 5.37 & 12.4 & 48.5 & 66.3 & 1.5 & $\mid 16.8$ & 0.85 & 2792 & 68.8 & \begin{tabular}{|l|}
123.2 \\
\end{tabular} & 51.2 & 243 & 98.1 & 73.2 & \begin{tabular}{|l|}
$\mid 13.2$ \\
\end{tabular} & 2069 & \\
\hline & 85 & 57.4 & 1405 & 6.1 & 27.2 & 46.4 & 30.3 & $\mid 124.6$ & 21.1 & 176 & 119.0 & 30.2 & 41.2 & & 0.0 & 11.7 & 2.20 & 17.5 & & 12.4 & 48.5 & 3 & 1 & 16.8 & 0.85 & 279 & & 23.2 & 51.2 & & 98. & & 2 & & period \\
\hline & 85 & & & & 31.3 & 38.6 & 66.8 & 54.3 & 21.9 & 143 & 66.6 & 35.7 & 42.9 & 0.0 & & 11.7 & & 21.7 & & 14.1 & 41.7 & & 1 & 15.5 & & & & & & & & & & & \\
\hline $4-5$ & 85 & 57.6 & $\mid 1225$ & \begin{tabular}{|l|}
$\mid$ \\
$\mid$
\end{tabular} & 22.5 & 33.9 & 57.7 & 54.4 & $\mid 17.9$ & 130 & 50.0 & 35.5 & 40.8 & 0.0 & 0.0 & 11.5 & 1.88 & 21.7 & 8.10 & 14.1 & 41.7 & $\mid 64.0$ & 1.3 & 15.5 & 1.13 & 2792 & 68.8 & 123.2 & 51.2 & 243 & 98.1 & 73.2 & 13.2 & 2106 & \\
\hline $5-6$ & 85 & 57.8 & 1000 & 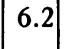 & 26.5 & 35.7 & 61.5 & 49.6 & $\mid 16.9$ & \begin{tabular}{|l|}
128 \\
\end{tabular} & 49.0 & 34.5 & 43.3 & 0.0 & 0.0 & 11.5 & 1.82 & 21.7 & 8.10 & 14.1 & 41.7 & 64.0 & 1.3 & 15.5 & 1.13 & 2792 & 68.8 & 123.2 & 51.2 & 243 & 98.1 & 73.2 & 13.2 & 2069 & \\
\hline
\end{tabular}


The foreperiod. After the patient had been on the above dietary regime for ten days, the experimental foreperiod with food, urine and stool analyses was begun. It is of clinical interest that this patient, whose stabilization with insulin had always been extremely difficult, in spite of accurately calculated diets on the Metabolism Service, remained sugar-free and showed no evidence of hypoglycemia when identical meals were eaten and his activities were kept constant. In the foreperiod, which lasted 12 days, the patient's weight fluctuated $\pm 0.2 \mathrm{kgm}$. (Table 1). While the daily fluid intake in the foreperiod remained approximately constant, the urine output showed considerable variation; the average daily positive balance was $1540 \mathrm{cc}^{2}$ The $\mathrm{pH}$ of the urine, in spite of the standardized conditions of the experiment, showed daily changes which were surprisingly great. The average daily $\mathrm{NH}_{3}$ excretion was 39.4 m.eq. and that of titratable acid was 28.6 m.eq. No correction was made for bicarbonate as the urine was sufficiently acid to make this a negligible factor. In the foreperiod a daily positive balance of inorganic base amounting to $29.5 \mathrm{~m}$.eq. was found. Of this, $21.2 \mathrm{~m}$.eq. represented $\mathrm{Na}+\mathrm{Mg}$ as determined by difference, 5.7 m.eq. were $\mathrm{K}$ and $2.6 \mathrm{~m}$.eq. were $\mathrm{Ca}^{3}$ Of the anions, 16.9 m.eq. of $\mathrm{Cl}$ and 0.03 gram of $\mathrm{P}$ were retained each day. There was a daily excretion of 46.3 m.eq. of inorganic sulphate. The patient was practically in nitrogen equilibrium, there being a positive balance of only 0.5 gram daily. There were only traces of ketones excreted in this period and while the creatinine excretion was at a high level for a patient weighing $59 \mathrm{kgm}$., the rate of excretion was fairly constant. The detailed analytical results of this period may be seen in Tables 1 and 2.

The period of insulin withdrawal. At the end of the foreperiod, insulin administration was terminated abruptly. Except for this change, the regime was carried on as before. On the first day the patient complained of slight dryness of the mouth. This symptom became progressively worse. After two days, he complained of weakness of his legs, slight nausea and he appeared apathetic. At the beginning of the fourth day without insulin, the symptoms were about the same but towards the end of this day he became obviously ill. Nausea was extreme; and the

${ }^{2}$ Upon the assumption that all the food ingested was absorbed and consumed completely, there were formed about $250 \mathrm{cc}$. of water per day. This water should be added to his fluid intake as measured, in order to give as accurately as possible the total amount of water which the body had to dispose of each day. In the foreperiod, the assumption that the food was completely consumed is probably not far from correct. In the acidosis period the food was obviously not all consumed, and there were undoubtedly profound changes in metabolic state, but such second-order differences as these changes might produce in the water available from catabolism of food substances can be neglected in the present discussion.

3 This apparent retention includes the electrolytes lost through the skin. 
TABLE 2

Summary of balance data obtained on the patient $T$. $M$.

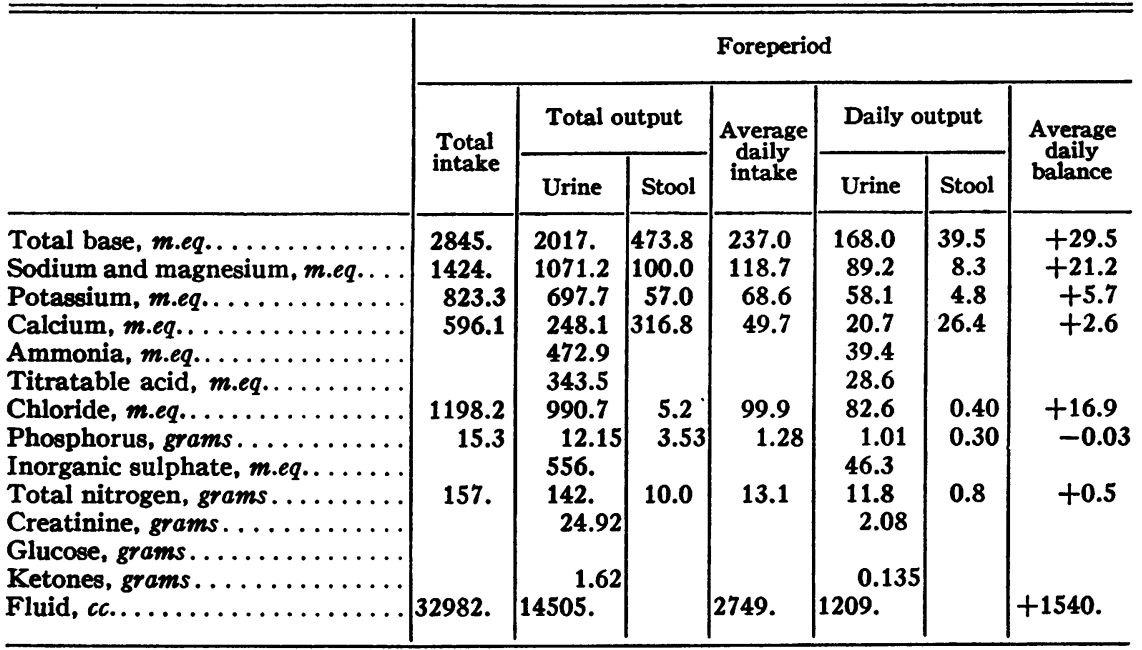

\begin{tabular}{|c|c|c|c|c|c|c|c|}
\hline & \multicolumn{7}{|c|}{ "Acidosis" period } \\
\hline & \multirow{2}{*}{$\begin{array}{c}\text { Total } \\
\text { intake }\end{array}$} & \multicolumn{2}{|c|}{ Total output } & \multirow{2}{*}{$\begin{array}{c}\text { Average } \\
\text { daily } \\
\text { intake }\end{array}$} & \multicolumn{2}{|c|}{$\begin{array}{c}\text { Average daily } \\
\text { output }\end{array}$} & \multirow{2}{*}{$\begin{array}{c}\text { Average } \\
\text { daily } \\
\text { balance }\end{array}$} \\
\hline & & Urine & Stool & & Urine & Stool & \\
\hline 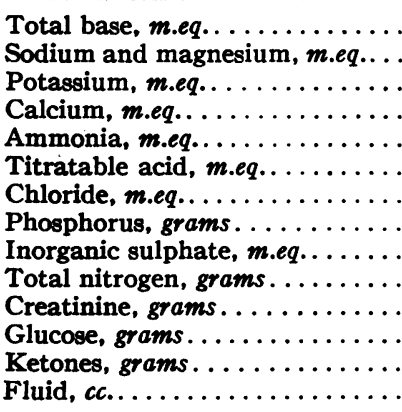 & \begin{tabular}{r|}
484.6 \\
4.83 \\
45.6 \\
\\
\\
1207.
\end{tabular} & \begin{tabular}{|c|}
1517. \\
695.3 \\
607.2 \\
214.5 \\
576.2 \\
383.1 \\
522.5 \\
7.89 \\
302.8 \\
74.7 \\
10.15 \\
598. \\
71.0 \\
10485.
\end{tabular} & $\begin{array}{r}217.6 \\
41.6 \\
17.0 \\
159.2\end{array}$ & $\begin{array}{c}239.2 \\
130.3 \\
65.4 \\
43.5 \\
\\
121.2 \\
1.21 \\
11.4 \\
\\
2802 .\end{array}$ & \begin{tabular}{|c|}
379.2 \\
173.8 \\
151.8 \\
53.6 \\
144.1 \\
95.8 \\
130.6 \\
1.97 \\
75.7 \\
18.7 \\
2.54 \\
150. \\
17.74 \\
2621.
\end{tabular} & $\begin{array}{r}54.4 \\
10.4 \\
4.2 \\
39.8\end{array}$ & $\begin{array}{r}-194.2 \\
-53.9 \\
-90.6 \\
-49.9\end{array}$ \\
\hline
\end{tabular}

patient rapidly developed epigastric pain, headache, restlessness and prostration. By midnight of this day, after the patient had vomited three times, his clinical picture became too grave to warrant further delay in restorative therapy. Consequently, he was given an infusion of 1000 cc. of physiological $\mathrm{NaCl}$ solution and received 40 units of insulin, followed by 10 units every hour for the next 17 hours. During the period of increasing acidosis, the patient forced himself to eat all his meals. The vomitus on the fourth day was collected and analyzed and appropriate corrections were made in the tables. Corrections were also made for the infusion. 
TABLE 2-Continued

Summary of balance data obtained on the patient $T$. M.

\begin{tabular}{|c|c|c|c|c|c|c|c|}
\hline \multirow{3}{*}{$\cdot$} & \multicolumn{7}{|c|}{ Recovery period I } \\
\hline & \multirow{2}{*}{$\begin{array}{l}\text { Total } \\
\text { intake }\end{array}$} & \multicolumn{2}{|c|}{ Total output } & \multirow{2}{*}{$\begin{array}{c}\text { Average } \\
\text { daily } \\
\text { intake }\end{array}$} & \multicolumn{2}{|c|}{$\begin{array}{c}\text { Average daily } \\
\text { output }\end{array}$} & \multirow{2}{*}{$\begin{array}{c}\text { Average } \\
\text { daily } \\
\text { balance }\end{array}$} \\
\hline & & Urine & Stool & & Urine & Stool & \\
\hline 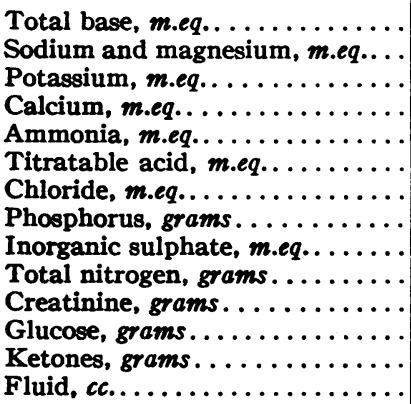 & $\begin{array}{c}1188.8 \\
598 . \\
352 . \\
238.4\end{array}$ & \begin{tabular}{|c|}
504. \\
329.6 \\
40.4 \\
134 \\
435.6 \\
91.8 \\
449.6 \\
3.62 \\
218.1 \\
56.8 \\
10.43 \\
0 \\
1.34 \\
5100
\end{tabular} & $\begin{array}{r}331.5 \\
62.1 \\
26.9 \\
242.5\end{array}$ & $\begin{array}{c}99.6 \\
1.28 \\
12.9 \\
\\
\end{array}$ & $\begin{array}{c}101 . \\
65.9 \\
8.1 \\
26.8 \\
87.1 \\
18.4 \\
89.4 \\
0.72 \\
43.6 \\
11.4 \\
2.09 \\
0 \\
0.27 \\
1020\end{array}$ & $\begin{array}{r}66.3 \\
12.4 \\
5.4 \\
48.5\end{array}$ & $\begin{array}{r}+70.4 \\
+41.3 \\
+56.9 \\
-27.6\end{array}$ \\
\hline
\end{tabular}

\begin{tabular}{|c|c|c|c|c|c|c|c|}
\hline & \multicolumn{7}{|c|}{ Recovery period II } \\
\hline & \multirow{2}{*}{$\begin{array}{l}\text { Total } \\
\text { intake }\end{array}$} & \multicolumn{2}{|c|}{ Total output } & \multirow{2}{*}{$\begin{array}{c}\text { Average } \\
\text { daily } \\
\text { intake }\end{array}$} & \multicolumn{2}{|c|}{$\begin{array}{l}\text { Average daily } \\
\text { output }\end{array}$} & \multirow{2}{*}{$\begin{array}{c}\text { Average } \\
\text { daily } \\
\text { balance }\end{array}$} \\
\hline & & Urine & Stool & & Urine & Stool & \\
\hline 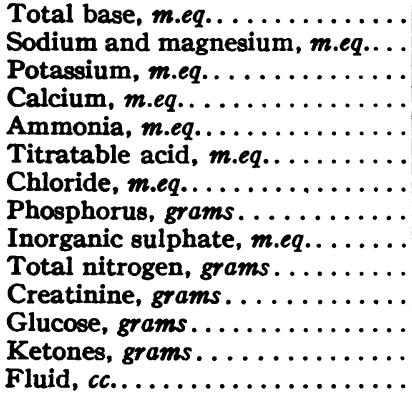 & $\begin{array}{c}392.4 \\
5.04 \\
52.8 \\
\\
1168 .\end{array}$ & \begin{tabular}{|l}
577. \\
283. \\
216.3 \\
77.8 \\
154.6 \\
107.5 \\
284.6 \\
3.55 \\
168.2 \\
46.4 \\
7.9 \\
0 \\
0 \\
4900
\end{tabular} & $\begin{array}{r}258.3 \\
55.1 \\
29.7 \\
173.5\end{array}$ & $\begin{array}{c}243 . \\
123.2 \\
68.8 \\
51.2 \\
\\
\\
98.1 \\
1.26 \\
\\
13.2\end{array}$ & \begin{tabular}{|c|}
144. \\
70. \\
54.1 \\
19.5 \\
38.7 \\
26.9 \\
71.2 \\
0.89 \\
42.1 \\
11.6 \\
1.99 \\
0 \\
0 \\
1225
\end{tabular} & $\begin{array}{r}64.6 \\
13.8 \\
7.4 \\
43.4\end{array}$ & $\begin{array}{c}+34.4 \\
+39.4 \\
+7.3 \\
-11.7 \\
\\
+25.6 \\
-0.09 \\
+0.5\end{array}$ \\
\hline
\end{tabular}

In the first 24 hours following the withdrawal of insulin, the patient lost $0.8 \mathrm{kgm}$. in weight, his urine output increased about $1000 \mathrm{cc}$. above the average for the foreperiod, whereas the $\mathrm{pH}$ of the urine, $\mathrm{NH}_{3}$ excretion and urine titratable acid showed no striking changes from the values observed in the control period, though the latter two were slightly augmented. There was on the first day of the "acidosis" period an increase of 80.4 m.eq. in the urinary excretion of potassium, and an increase of 87.1 m.eq. in the base fraction $\mathrm{Na}+\mathrm{Mg}$. The urinary calcium showed an increase of 10.5 m.eq. on this day. The anions $\mathrm{Cl}$ and $\mathrm{P}$ showed an increased urinary excretion of $66.8 \mathrm{~m} . e q$. and 0.72 gram respectively 
over the foreperiod, whereas $\mathrm{SO}_{4}$ increased 23.4 m.eq. The increase in urinary $\mathrm{N}$ on the first day was about 6 grams. During this 24-hour period the patient excreted 116 grams of glucose, 3.5 grams of ketone bodies and the creatinine excretion was greatly augmented. It is interesting to note that these striking changes occurred before there was significant "clinical acidosis" as measured by the bicarbonate content of the blood serum (Figure 1).

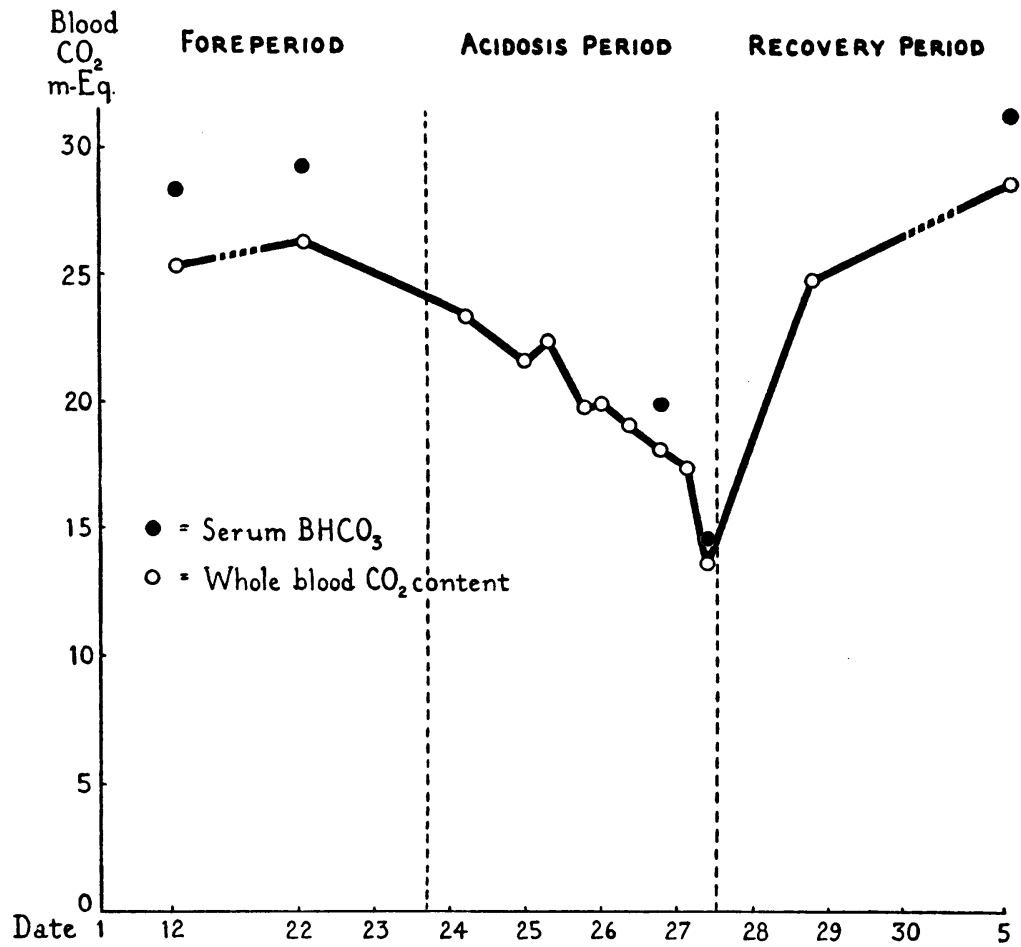

Fig. 1. Changes in the Blood Bicarbonate Concentration in the Patient T. M.

During the next three days of this period the body weight decreased at a rate of about a kilo a day, the urine $\mathrm{pH}$ became fixed at 5.4, the $\mathrm{NH}_{3}$ excretion increased progressively as did the titratable acid. The loss of $\mathrm{K}$ and the base fraction $\mathrm{Na}+\mathrm{Mg}$ from the body decreased slightly on the second day without insulin and then mounted rapidly to a peak on the fourth day. The loss of $\mathrm{Ca}$ increased progressively. There was augmentation of the $\mathrm{Ca}$ of both urine and stool. Phosphorus excretion continued to rise during the period of acidosis, the entire change being due to an increase in urinary output. The rate of inorganic sulphate excretion showed but a small additional increase after the rise of the first day, and this was true also of the nitrogen excretion. As might be 
anticipated, the ketones in the urine mounted progressively, 31.2 grams being eliminated on the fourth day. Glucose excretion reached 171 grams on the third day. The decrease in the last twenty-four hours of the period was probably due to the fact that the administration of insulin was begun six hours before the period was closed.

The more striking changes in excretion observed in this patient during the development of acidosis may be summarized as follows: Upon the withdrawal of insulin, there occurred a rapid loss of body weight and water, the average daily urine excretion increasing by about $1100 \mathrm{cc}$. The urine $\mathrm{pH}$ became fixed at 5.4 and the $\mathrm{NH}_{3}$ and titratable acid increased rapidly and progressively after the first twenty-four hours. There was a change from a daily positive inorganic base balance of $29.5 \mathrm{~m}$.eq. in the foreperiod to a daily negative balance of $194.2 \mathrm{~m}$.eq. The loss of $\mathrm{K}$ was even greater than that of the base fraction $\mathrm{Na}+\mathrm{Mg}$ and both began to be excreted in large amounts before any striking drop occurred in the blood bicarbonate level and twenty-four hours before any significant increase in $\mathrm{NH}_{3}$ excretion occurred. Calcium excretion increased progressively as did the $\mathrm{NH}_{3}$ output, the balance of the former changing from $+2.6 \mathrm{~m}$.eq. to an average value of -49.9 m.eq. during the acidosis period. The inorganic anions, $\mathrm{Cl}, \mathrm{PO}_{4}, \mathrm{SO}_{4}$, all showed considerable increase in the rate of excretion but this was not equivalent to the loss of base, the discrepancy being largely accounted for by ketone excretion. The glucose excretion during the acidosis period exceeded the carbohydrate intake and was approximately equivalent to the carbohydrate of the diet plus 58 per cent of the ingested protein.

Recovery period. Within eighteen hours after insulin was again administered, the patient became symptom-free. The changes in the electrolyte balances were striking and in general were the reverse of those resulting from insulin withdrawal. At the end of five days, equilibrium in the body was nearly reestablished at the level of the control period.

The patient was unable to complete the twenty-four-hour urine specimen at the end of the first day of recovery and consequently it seems advisable for purposes of discussion to combine the analytical data of the first two days of the period. During these two days he gained 2.8 $\mathrm{kgm}$. in weight and excreted about $780 \mathrm{cc}$. of urine daily, the positive water balance being $2010 \mathrm{cc}$. daily in contrast with $1540 \mathrm{cc}$. in the foreperiod and $180 \mathrm{cc}$. in the acidosis period. The fluid balance then gradually returned to normal. The urine $\mathrm{pH}$ returned to normal levels within twenty-four hours, whereas the excretion of $\mathrm{NH}_{3}$ remained greatly increased for several days, though it gradually declined, reaching the level of the foreperiod on the fifth day. The titratable acid fell from 141.1 m.eq. on the last day of the acidosis period to an average slightly below normal on the first two days of the recovery period. This change accompanied the almost complete disappearance of ketone bodies on the first day. 
Perhaps the most striking event in the recovery period was the retention of $\mathrm{K}$ and of the base fraction $\mathrm{Na}+\mathrm{Mg}$. Whereas the daily urinary excretion of the former was $58.1 \mathrm{~m}$.eq. and of the latter was $\mathbf{8 9 . 2}$ m.eq. in the foreperiod, as compared with $173.8 \mathrm{~m}$.eq. and $151.8 \mathrm{~m}$.eq. in the acidosis period, the average elimination on the first two days of the recovery period was 4.8 m.eq. and 5.3 m.eq., respectively. The retention of potassium was more prolonged than that of the base fraction $\mathrm{Na}+\mathrm{Mg}$. The storage of $\mathrm{Na}$ and $\mathrm{K}$ for the replacement of intra- and extra-cellular fluid stores began immediately after insulin therapy was reinstituted and when ketone formation ceased. Calcium loss continued, however, for some days. Although loss of $\mathrm{Ca}$ through the bowel was greater than that through the kidneys, both continued to be augmented above the level of the foreperiod. In contrast to the sudden and marked retention of base in the recovery period, the retention of the $\mathrm{Cl}$ ion was much less striking, as might be anticipated from the fact that the loss of this anion was far less than that of the cations $\mathrm{Na}$ and $\mathrm{K}$ in the period of acidosis. It is interesting to note that there was no retention of $P$ in the recovery period in spite of the loss of 1.16 gram daily during the period of insulin withdrawal. This may suggest a relationship to the behavior of $\mathrm{Ca}$ and is possibly the result of continued loss of substance from osseous tissue. The urinary sulphates returned to the level of the foreperiod within two days after insulin therapy was again begun, as did the excretion of nitrogen. There was no apparent regeneration of protein in the nine days of the recovery period to make up for the 32 grams of nitrogen lost in the period of insulin withdrawal.

Analysis of the balance study. The foregoing has been a general description of the changes encountered during the development of diabetic acidosis and in recovery following the reestablishment of insulin treatment. An attempt to analyze the processes of electrolyte and water readjustment within the body itself which would include an allocation between cells and tissue spaces has proven almost impossible because of the lack of certain essential data. First of all, published estimations of the actual chemical composition of intracellular fluid in the human are open to criticism as such analyses have always included a certain amount of intercellular fluid. In the second place, little is known of the qualitative and quantitative losses of electrolytes through the skin of human beings under different conditions in the insensible and sensible perspiration. A series of calculations (Tables 3 and 4) have been made from the data obtained from the study of this patient which clearly demonstrate some of the interpretative difficulties encountered. It was stated in the description of the twelve-day foreperiod that there was definite daily "retention" of $\mathrm{K}$, of the base fraction $\mathrm{Na}+\mathrm{Mg}$, and of $\mathrm{Cl}$ (c.f. Tables 1 and 2), and a similar "retention" of $1540 \mathrm{cc}$. of water. As the patient was in nitrogen equilibrium and maintained his weight at a 


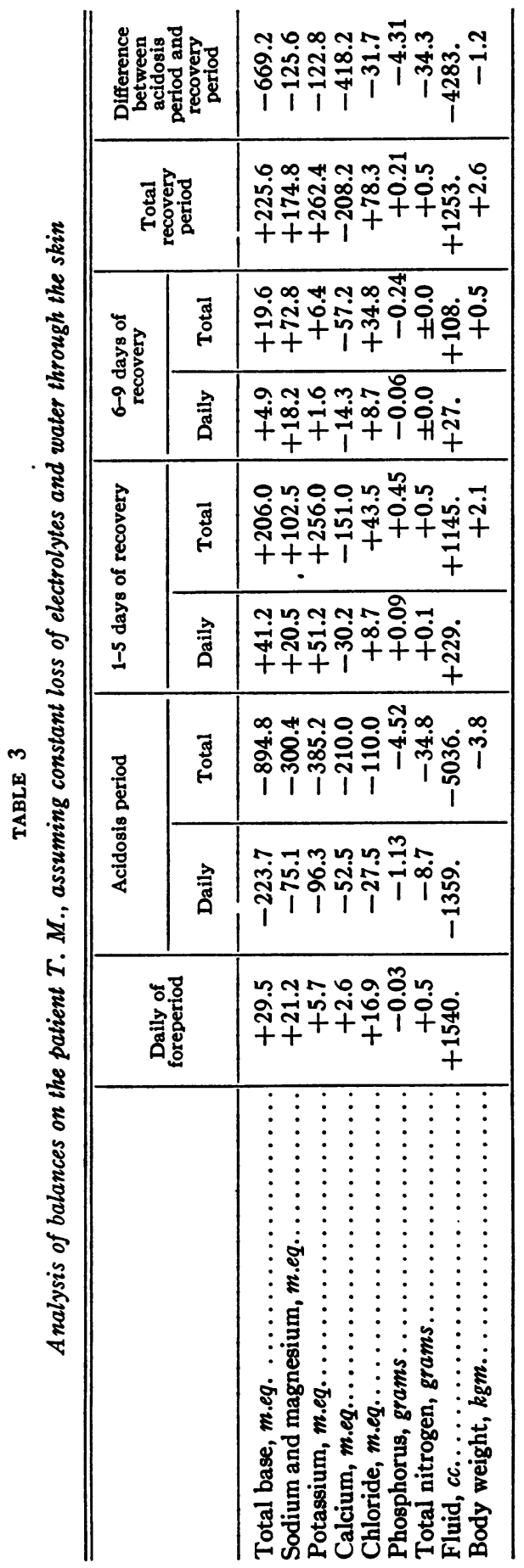


constant level, this "retention" presumably represented chiefly the loss of water and salts through lungs or skin. ${ }^{4}$ In Table 3, the total balances have been calculated with the assumption that the loss of electrolytes, water and nitrogen through the skin was the same in the acidosis and recovery periods as in the foreperiod. For purposes of comparison, the balances have also been calculated (as shown in Table 4), assuming no loss of electrolytes, water or nitrogen through the skin. Thus, if it be assumed that the skin losses throughout the experiment were constant, difficulties with the observed facts are at once encountered. For example, the net loss in body weight in the combined acidosis and recovery periods was $1.2 \mathrm{kgm}$., yet when calculated on the basis of the above assumption, the net loss of water from the body would have been about 4.3 liters (Table 3). In other words, the rate of water excretion through the skin in the acidosis and recovery periods was so greatly diminished that about 3.1 liters less were lost from the body than if the rate of skin loss had been maintained at the level of the foreperiod. In view of the fact that the patient was not hyperpneic, there is no reason to assume that the loss of water through the lungs was increased in the period of acidosis. In applying this same reasoning to the behavior of the electrolytes, $\mathrm{K}$ and the base fraction $\mathrm{Na}+\mathrm{Mg}$, one finds the state of affairs quite different. The net loss in body weight, as stated above, was 1200 grams. Since about 200 grams of this weight represent protein lost from the body and not replaced (about 32 grams of nitrogen), the loss of body water was about one liter which should contain approximately 150 m.eq. of base. The net loss of $\mathrm{K}+\mathrm{Na}+\mathrm{Mg}$ in the acidosis and recovery periods, assuming constant skin loss, was about 250 m.eq. Thus the discrepancy between the calculated and observed negative balance was about 100 m.eq. or about 7.5 m.eq. daily, a figure well within the limits of error in a balance study. The net loss of $\mathrm{K}+\mathrm{Na}+\mathrm{Mg}$ might thus be accounted for on the basis of base lost from the body with protein. From this it may perhaps be concluded that the loss of $\mathrm{K}$ and the base fraction $\mathrm{Na}+\mathrm{Mg}$ through the skin was approximately constant in the fore, acidosis and recovery periods, whereas the loss of water was far less in the acidosis and recovery periods than in the foreperiod. In respect to the $\mathrm{Cl}$ balances, the figures are somewhat similar to those of the cations just mentioned. The net loss was 31 m.eq., whereas the expected loss with $1 \mathrm{kgm}$. of body water would be about $100 \mathrm{~m} . e q$. , leaving a discrepancy of 70 m.eq. in the direction of excess storage of chloride in contrast to base. It may, therefore, be concluded that the concentration of electrolytes in the insensible perspiration varied enormously depending upon the water requirements of the milieu interrieur of the body. Thus

${ }^{4}$ Water in the stools was not determined, but, as the patient was slightly constipated throughout the period of observation, this source of error was probably small and essentially constant. 


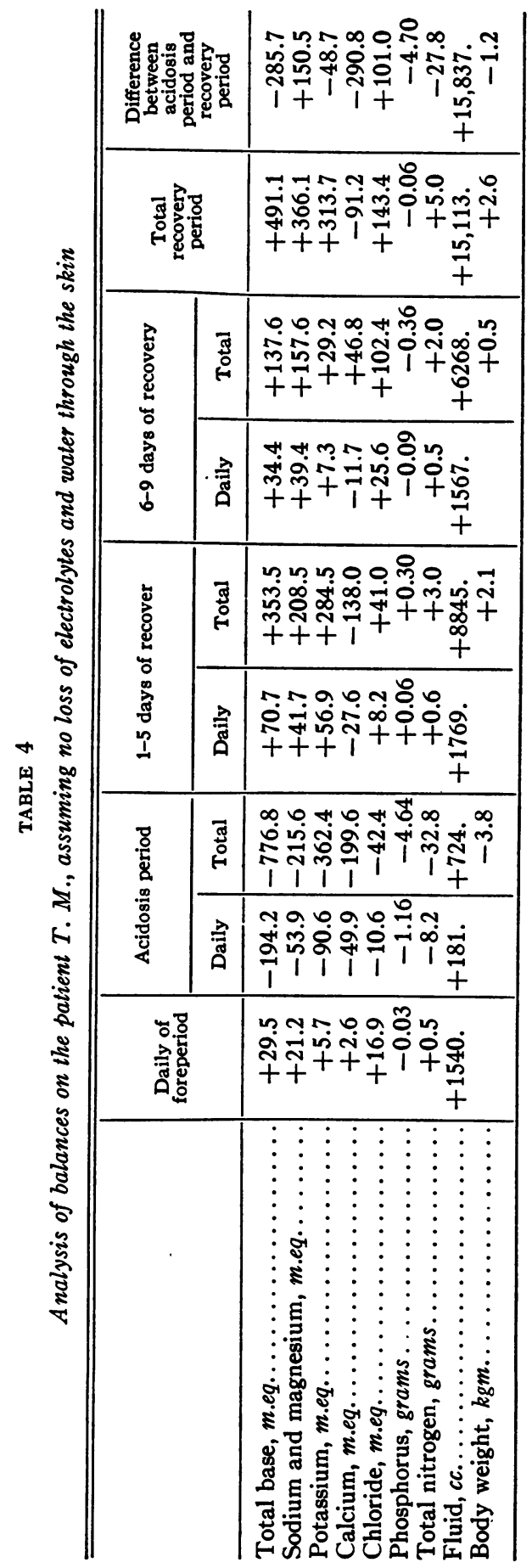




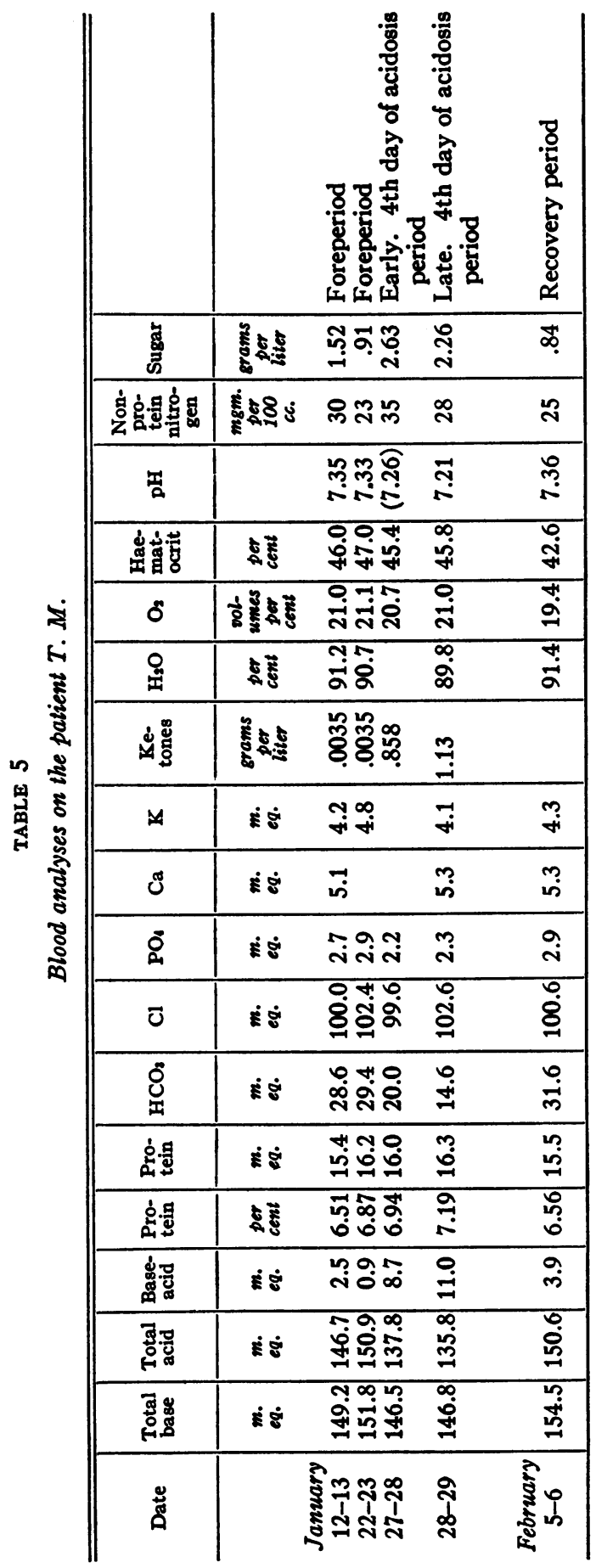


the contrast in the behavior of water and electrolytes is striking and emphasizes the importance of the consideration of the skin losses in any balance study. ${ }^{5}$ The large net loss of total fixed base in the acidosis and recovery periods combined (Table 3 ) was due chiefly to the persistent loss of calcium from the body. This presumably came from the bones and consequently is not a factor of significance in a consideration of water balance and of electrolyte structure.

Blood changes during the period of acidosis. As seen in Table 5, the electrolytes of the blood serum showed normal concentrations during the foreperiod. B-A ${ }^{6}$ in the first sample was 2.5 m.eq. and in the second sample 0.9 m.eq. There were no ketones in these two blood specimens taken during the foreperiod. The third line of the table shows the serum concentrations at the beginning of the fourth day of acidosis, and the next line the concentrations at 12:50 a.m. of the same twenty-four-hour period, when acidosis was at its height. Both sets of analyses show the characteristic changes of a moderately severe diabetic acidosis. These include (1) small but definite fall in total base and total acid concentration, (2) sharp increase in B-A, associated with rise in blood ketones to about 1.0 gram per liter (the anion-equivalent of the ketones was not included in the summation of the anions, A), (3) fall in $\mathrm{HCO}_{3}$, approximately equal to the B-A increase (ketones), plus the decrease in total base, (4) fall in serum $\mathrm{pH}$, from 7.33 to 7.21 , that is, the development of an uncompensated acidosis, (5) increase in the blood sugar to 2.63 grams per liter and (6) decrease in water content from 91.2 per cent to 89.8 per cent.

During the recovery period, as shown in the serum figures of February 5 th, the blood was restored to the foreperiod values, except for minor differences.

These alterations in the blood have been frequently described in other studies of diabetic acidosis and require no comment.

For obvious reasons, it was not possible to obtain blood for complete serum electrolyte study on each day of the acidosis period. The course of the development of the acidosis was, however, followed by frequent determinations of whole blood $\mathrm{CO}_{2}$ content, as shown in Figure 1. It is interesting to note how closely the $\mathrm{CO}_{2}$ values paralleled the patient's clinical condition. Thus, there was a steady and nearly linear fall in $\mathrm{CO}_{2}$ level for three and a half days, during which the patient's general condition, though failing, remained relatively good. In the last six hours,

${ }^{5}$ It should be pointed out that equilibrium was essentially reestablished with regard to water and electrolyte balances by the end of the observations, as the patient's weight became almost constant and water and electrolyte excretion was again similar to that of the foreperiod.

- By the expression $\mathrm{B}-\mathrm{A}$ is meant the difference between the total inorganic base and the sum of the anions $\mathrm{Cl}, \mathrm{HCO}_{3}, \mathrm{PO}_{4}$, and protein expressed in milliequivalents. 
there was a sudden drop in $\mathrm{CO}_{2}$ of 3.6 m.eq., coincident with the rapid onset of symptoms of acute and serious acidosis.

\section{Patient W. O'C., number 242209}

This patient was a white man of 25 , who developed diabetes mellitus at the age of 24 . He had been in the hospital at 20 for the repair of a hernia and again at 21 for excision of a thyroglossal cyst. The onset of his diabetes was complicated by mild hyperthyroidism and a basal metabolic rate of +27 . With rest and regulation of diabetes this promptly subsided and a few weeks later the basal metabolic rate was +8 . Prior to admission to the Research Service for the work recorded in this paper, he was being treated in the out-patient department, requiring 86 units of insulin on a diet of 340 grams of carbohydrate, 70 grams of protein and 90 grams of fat. On admission, physical examination was negative. His basal metabolic rate was +16 per cent. Blood counts were normal. During the entire experiment the pulse rate varied between 78 and 88.

A regime identical with that followed in the case T. M. was instituted except that the diet contained 165 grams of carbohydrate, 87 grams of protein and 155 grams of fat until March 12 th, when it was changed to 186 grams of carbohydrate, 91 grams of protein, and 156 grams of fat. The insulin varied from 65 to 90 units as may be seen in Table 6. All analyses were carried out as in case T. M.

During the foreperiod, from about March 15th to March 19th, the patient suffered from a mild coryza, and began to show a slight glycosuria requiring readjustment of insulin dosage. On March 15th the temperature which had varied between $98.0^{\circ}$ and $99.6^{\circ}$ by rectum, rose to $100^{\circ}$ and reached the same height on March 17th, but there were no further clinical disturbances of significance.

The foreperiod. The foreperiod was preceded by eleven days of preliminary adjustment and was continued for sixteen days. The long duration of the foreperiod was due to the interference of the respiratory infection described above. During the first eleven days the patient's weight fell from $56.2 \mathrm{kgm}$. to $55.0 \mathrm{kgm}$. and during the remaining five days rose to $56.2 \mathrm{kgm}$. With a fluid intake which was practically constant ( $2788 \mathrm{cc}$. to $2836 \mathrm{cc}$.), the urine output ranged from $1110 \mathrm{cc}$. to 2030 cc. There was an average daily positive balance of $1278 \mathrm{cc}$. The $\mathrm{pH}$ of the urine varied from 5.5 to 6.2 . There was an average daily $\mathbf{N H}_{3}$ excretion of 33.7 m.eq. and the daily titratable acidity was 35.4 m.eq. Total inorganic base showed an average positive balance of $22.7 \mathrm{~m}$.eq. per day, of which 20.0 m.eq. were $\mathrm{Na}+\mathrm{Mg}$ (by difference), 2.1 m.eq. were $\mathrm{K}$ and 0.6 m.eq. was Ca (see footnote 3). A similar "retention" of 11.3 m.eq. of $\mathrm{Cl}$ and a loss of 0.08 gram of $\mathrm{P}$ daily were observed. The average urinary excretion of inorganic sulphate was $52.4 \mathrm{~m}$. .eq. Nitrogen 
equilibrium was satisfactory with a balance of -0.3 gram of $N$ per day. Qualitative tests for ketones in the urine were negative throughout the foreperiod. Creatinine excretion varied from 1.90 gram to 2.17 grams. Tables 6 and 7 give the detailed results obtained in the foreperiod.

No striking or consistent effect of the respiratory infection on the electrolyte balances could be discovered in our results. On the day after the cold was clinically apparent, the excretion of $\mathrm{Na}+\mathrm{Mg}$ and of $\mathrm{Cl}$ rose 20 to $30 \mathrm{~m}$.eq. above the preceding levels and the following day there was a decrease which was relatively much greater than the increase. In the first day there was a loss of $0.4 \mathrm{kgm}$. of body weight and in the second an equal gain. No significant change in $\mathrm{K}$ excretion occurred and urinary volume did not vary to any unusual degree. It might be inferred that during the height of the cold a loss of $\mathrm{NaCl}$ and water occurred with subsequent replacement; however, the results are not sufficiently clearcut to warrant interpretation.

The period of insulin withdrawal. ${ }^{7}$ There was little symptomatic response in this patient to the withdrawal of insulin; he complained of thirst on the second day but this manifestation subsided and no subjective evidence of ketosis appeared. No vomiting occurred and no infusions were necessary; the patient consumed his diet without difficulty. Glycosuria appeared on the first day, and maintained a relatively constant level of 125 grams a day after the first day. This may be compared with an intake of 186 grams of carbohydrate ingested as such, and 54 grams available from the protein of the diet. Although no significant quantity of ketone bodies appeared in the urine for several days, organic acids increased definitely in the first twenty-four hours of this period.

In the first forty-eight hours of the "acidosis" period, the patient lost $1.8 \mathrm{kgm}$., and the urine output was $1600 \mathrm{cc}$. above the previous average. The $\mathrm{pH}$ shifted strikingly towards the alkaline side ( $\mathrm{pH} 5.8$ to $\mathrm{pH} 6.4$ ), nitrogen excretion increased (14.4 grams to 17 to 18 grams), $\mathrm{NH}_{3}$ and titratable acid were constant and phosphate, sulphate and organic acid output increased. Calcium excretion increased definitely but the most marked changes were in the base fraction $\mathrm{Na}+\mathrm{Mg}, \mathrm{K}$ and $\mathrm{Cl}$. All of these changes occurred before ketones appeared in the urine in significant amounts. Consideration of stool excretion is not necessary at this point as no important changes took place in this period except for the increased output of Ca.

The first electrolyte to reach its maximum excretion in the "acidosis" period was potassium, which increased from an average of $66.6 \mathrm{~m}$.eq. in the foreperiod to $101.0 \mathrm{~m}$.eq. on the first day, dropping to $97.4 \mathrm{~m}$.eq. the next day, with an average of $81.4 \mathrm{~m}$.eq. for the entire period. The second twenty-four hours found a maximum reached for $\mathrm{Na}+\mathrm{Mg}, \mathrm{Ca}, \mathrm{Cl}, \mathrm{P}$,

7 In this section the period of insulin withdrawal and "acidosis" period are used synonymously. 
urine volume and weight loss. The urinary base fraction $\mathrm{Na}+\mathrm{Mg}$ rose from an average of $85.6 \mathrm{~m}$.eq. in the foreperiod to $176.5 \mathrm{~m}$.eq. on the first day and $218.6 \mathrm{~m}$.eq. on the second day, with an average for the "acidosis" period of 121.5 m.eq., although there were many unexplained fluctuations during the latter part of this period $(71.4$ m.eq. to 124.0 m.eq.). Chloride excretion also was much augmented during the "acidosis" period, reaching a maximum in the first two days. The average output in the foreperiod was $88.0 \mathrm{~m}$.eq. and in the "acidosis" period 107.9 m.eq. On the first day of the latter period there were 157.4 m.eq. in the urine and on the second $201.0 \mathrm{~m}$.eq., showing the same delayed peak as did $\mathrm{Na}+\mathrm{Mg}$ and $\mathrm{Ca}$. Of a total weight loss of $3.6 \mathrm{kgm}$. in eleven days, $1.2 \mathrm{kgm}$. occurred during this second day. Calcium excretion which had averaged $12.6 \mathrm{~m}$.eq. in the urine in the foreperiod rose to 22.0 m.eq. the first day and 24 m.eq. the second, averaging 20.4 m.eq. for the entire period. The daily urinary phosphorus excretion rose from 1.06 gram in the foreperiod to 1.35 gram in the period of insulin withdrawal. Urinary ammonia was not significantly altered until the third day, in fact, was lower the first day than at any time in the foreperiod $(29.0 \mathrm{~m}$.eq. as compared with a foreperiod average of 33.7 m.eq.). It reached its maximum of 56.3 m.eq. on the last day of the "acidosis" period. There was no significant parallelism between the increase in $\mathrm{NH}_{3}$ excretion and the steadily rising ketonuria, although the actual amount of ketones in the urine at the height of the "acidosis" period was only 1.35 gram in twenty-four hours.

As average daily balances in the foreperiod and "acidosis" period are compared, one notes that the following shift from positive to negative (not including skin loss). Total base: +22.7 m.eq. to -41.9 m.eq.; $\mathrm{Na}+\mathrm{Mg}:+20.0$ m.eq. to -14.1 m.eq.; $\mathrm{K}:+2.1$ m.eq. to -14.4 m.eq.; $\mathrm{Ca}:+0.6$ m.eq. to -13.3 m.eq.; $\mathrm{Cl}:+11.3$ m.eq. to -4.0 m.eq. The greater relative increase in the excretion of base over chloride in this patient can not be correlated with the appearance of ketones, in contrast to the observation in the patient T. M. A nitrogen balance of -0.3 gram daily in the foreperiod became -3.7 grams in the "acidosis" period.

The phenomena observed upon the withdrawal of insulin in this patient may be summarized as follows: First of all, a sharp loss in weight, due to loss of body water accompanied by its normal electrolytes. In two days the peak of this loss was reached and there then followed a less marked, but in relation to the foreperiod, a continuously elevated excretion of $\mathrm{Na}+\mathrm{Mg}, \mathrm{K}, \mathrm{Ca}, \mathrm{Cl}$ and $\mathrm{P}$. During the third day, appreciable amounts of ketone bodies appeared in the urine and at the same time an increase in $\mathrm{NH}_{3}$ excretion and titratable acidity. Fluid and inorganic electrolyte changes appeared to be related to glycosuria rather than to the insignificant ketosis. Within twenty-four hours after the withdrawal of insulin, the urinary nitrogen excretion increased about 3 grams and 
remained at this augmented level throughout the period. The organic acids of the urine which had remained at a relatively constant level throughout the foreperiod increased abruptly, reaching the maximum on the sixth day of the period. This increase preceded the appearance of ketones and also preceded the rise in ammonia excretion. The amount of organic acids in the urine showed no correlation with ketone body excretion.

Recovery period $I$. The recovery period has been subdivided into two periods of four days each, the first of which includes the more striking manifestations of the return to normal. The patient was sugar-free on the third day, and ketosis decreased immediately from 1.35 gram on the last day of the "acidosis" period to 0.33 gram on the first day of recovery. As in the "acidosis" period, the first forty-eight hours produced the greatest quantitative effect on the water and electrolyte balances. The gain in body weight in the first two days of the period was $1.8 \mathrm{kgm}$. and the total gain in eight days was $2.6 \mathrm{kgm}$. Accompanying this was a decrease in the urine volume. In contrast with an average daily urine output of $2004 \mathrm{cc}$. in the "acidosis" period and $1278 \mathrm{cc}$. in the foreperiod, the average daily output for the first forty-eight hours of the recovery period was $625 \mathrm{cc}$.

Associated with this decrease in urine volume there is retention of $\mathrm{Na}+\mathrm{Mg}$ (as seen in Tables 6 and 7.) From an average daily urinary output of 121.5 m.eq. in the "acidosis" period, there was a drop to 33.2 m.eq. the first day and 10.4 m.eq. the second day, with an average for recovery period I of 34.9 m.eq. The retention of $\mathrm{K}$ was clearly shown by the decreased urinary excretion in the first two days. The average daily positive balance for recovery period I was significantly higher than that of the foreperiod, +15.9 m.eq. in the former as compared with +2.1 m.eq. in the latter. Chloride excretion in the urine decreased from an average daily figure of 107.9 m.eq. to 26.7 m.eq. the first day and 10.8 m.eq. the second day, while the average excretion for the entire recovery period I was 32.2 m.eq. A mild glycosuria persisted during these two days of water, base and $\mathrm{Cl}$ replacement. When total balances are considered one finds that the base fraction $\mathrm{Na}+\mathrm{Mg}$ showed an average daily positive balance of $+64.1 \mathrm{~m}$.eq. in the first recovery period as compared to +20.0 m.eq. in the foreperiod and -14.7 m.eq. in the "acidosis" period. The $\mathrm{Cl}$ balances follow the same trends, with a daily positive balance of $+\mathbf{1 1 . 3}$ m.eq. in the foreperiod, a negative balance of -4.0 m.eq. in the "acidosis" period and a positive balance of $+67.1 \mathrm{~m}$.eq. in the first recovery period. Phosphate excretion dropped sharply to a level somewhat below that of the foreperiod but in three or four days had returned to the initial level. A positive phosphorus balance existed for the first time in the experiment during the recovery periods. Urinary sulphate excretion diminished at once upon the restoration of insulin 
TABLE 7

Summary of the balance data obtained on the patient $W . O^{\prime} C$.

\begin{tabular}{|c|c|c|c|c|c|c|c|}
\hline & \multicolumn{7}{|c|}{ Foreperiod } \\
\hline & \multirow{2}{*}{$\begin{array}{l}\text { Total } \\
\text { intake }\end{array}$} & \multicolumn{2}{|c|}{ Total output } & \multirow{2}{*}{$\begin{array}{c}\text { Average } \\
\text { daily } \\
\text { intake }\end{array}$} & \multicolumn{2}{|c|}{$\begin{array}{c}\text { Average daily } \\
\text { output }\end{array}$} & \multirow{2}{*}{$\begin{array}{c}\text { Average } \\
\text { daily } \\
\text { balance }\end{array}$} \\
\hline & & Urine & Stool & & Urine & Stool & \\
\hline 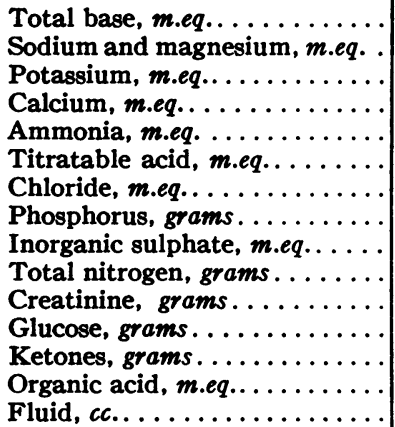 & $\begin{array}{r}1593.8 \\
23.12 \\
240.2 \\
\\
\\
\\
45018 .\end{array}$ & \begin{tabular}{|c|}
2637.3 \\
1370.2 \\
1065.4 \\
201.7 \\
539. \\
565.9 \\
1407.9 \\
16.88 \\
838.1 \\
229.9 \\
33.27 \\
\\
716.8 \\
24580.
\end{tabular} & $\begin{array}{r}1015.2 \\
185.8 \\
133.2 \\
696.2 \\
\\
5.2 \\
7.57 \\
14.70\end{array}$ & \begin{tabular}{|c}
250.9 \\
117.2 \\
77.0 \\
56.7 \\
\\
99.6 \\
1.45 \\
15.0
\end{tabular} & $\begin{array}{c}164.8 \\
85.6 \\
66.6 \\
12.6 \\
33.7 \\
35.4 \\
88.0 \\
1.06 \\
52.4 \\
14.4 \\
2.08 \\
0 \\
44.8 \\
1536\end{array}$ & $\begin{array}{r}63.5 \\
11.6 \\
8.3 \\
43.5\end{array}$ & $\begin{array}{r}+11.3 \\
-0.08 \\
-0.3\end{array}$ \\
\hline
\end{tabular}

\begin{tabular}{|c|c|c|c|c|c|c|c|}
\hline & \multicolumn{7}{|c|}{ Period of insulin withdrawal } \\
\hline & \multirow{2}{*}{$\begin{array}{l}\text { Total } \\
\text { intake }\end{array}$} & \multicolumn{2}{|c|}{ Total output } & \multirow{2}{*}{$\begin{array}{c}\text { Average } \\
\text { daily } \\
\text { intake }\end{array}$} & \multicolumn{2}{|c|}{$\begin{array}{l}\text { Average daily } \\
\text { output }\end{array}$} & \multirow{2}{*}{$\begin{array}{c}\text { Average } \\
\text { daily } \\
\text { balance }\end{array}$} \\
\hline & & Urine & Stool & & Urine & Stool & \\
\hline 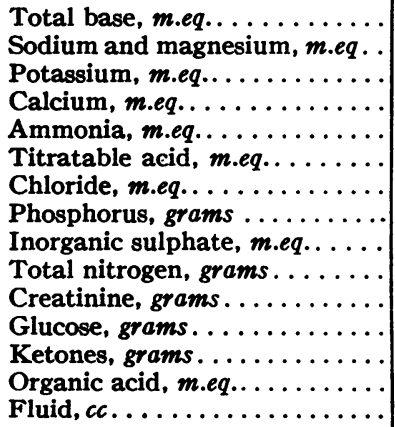 & \begin{tabular}{r|}
2738.2 \\
1327.8 \\
812.0 \\
597.8 \\
\\
1144.6 \\
15.67 \\
170.3 \\
\\
\\
30938.
\end{tabular} & \begin{tabular}{|c|}
2456.3 \\
1336.5 \\
895.7 \\
224.1 \\
489.7 \\
528.3 \\
1187.0 \\
14.80 \\
774.3 \\
201.1 \\
24.61 \\
1376.8 \\
5.31 \\
1073.1 \\
22040.
\end{tabular} & $\begin{array}{c}2.5 \\
5.15 \\
10.24\end{array}$ & $\begin{array}{r}104.1 \\
1.42 \\
15.52\end{array}$ & $\begin{array}{c}223.3 \\
121.5 \\
81.4 \\
20.4 \\
44.5 \\
48.0 \\
107.9 \\
1.35 \\
70.4 \\
18.3 \\
2.24 \\
125.2 \\
0.48 \\
97.6 \\
2004 .\end{array}$ & $\begin{array}{r}67.5 \\
13.3 \\
6.9 \\
47.2\end{array}$ & $\begin{array}{l}-41.9 \\
-14.1 \\
-14.4 \\
-13.3\end{array}$ \\
\hline
\end{tabular}

therapy, falling to the level of the foreperiod. Nitrogen equilibrium was also almost immediately reestablished with an average daily balance of +0.41 gram for the period. Calcium loss continued until recovery period II, the balances being: foreperiod, +0.6 m.eq., acidosis period, -13.3 m.eq., recovery period I, -13.9 m.eq. and recovery period II, +11.6 m.eq. This sequence of $\mathrm{Ca}$ balances is largely dependent on changes in stool $\mathrm{Ca}$ excretion, for urinary $\mathrm{Ca}$ excretion tended to parallel 
TABLE 7-Continued

Summary of the balance data obtained on the patient W. O'C.

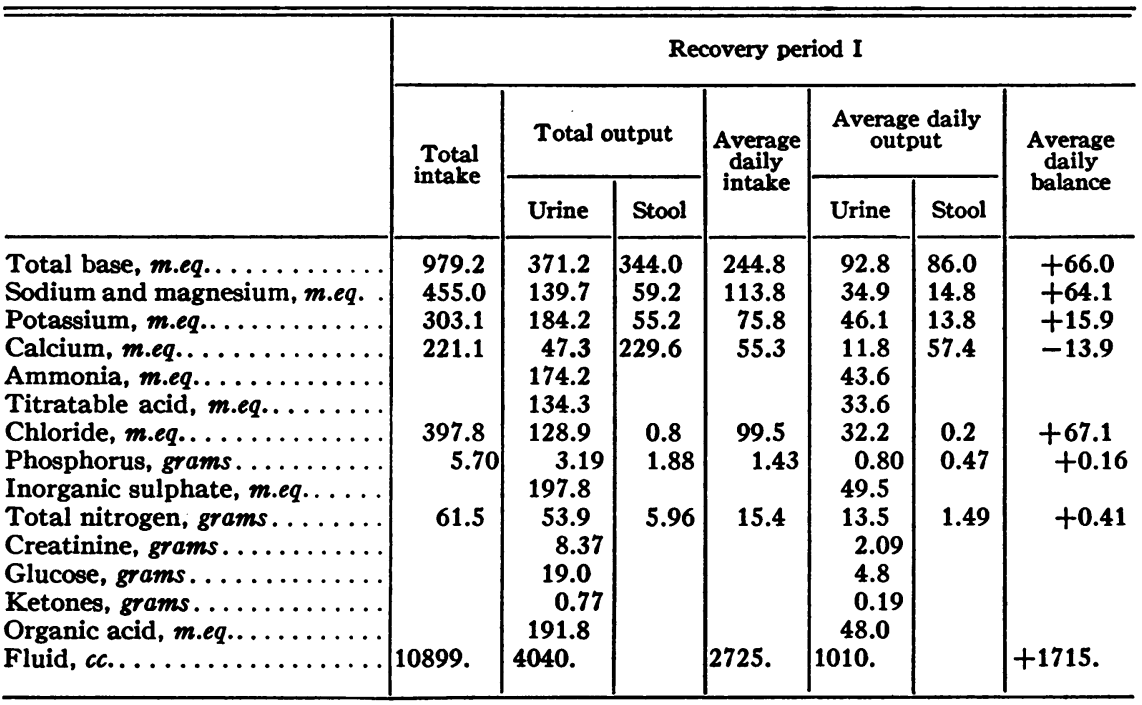

\begin{tabular}{|c|c|c|c|c|c|c|c|}
\hline & \multicolumn{7}{|c|}{ Recovery period II } \\
\hline & \multirow{2}{*}{$\begin{array}{l}\text { Total } \\
\text { intake }\end{array}$} & \multicolumn{2}{|c|}{ Total output } & \multirow{2}{*}{$\begin{array}{c}\text { Average } \\
\text { daily } \\
\text { intake }\end{array}$} & \multicolumn{2}{|c|}{$\begin{array}{l}\text { Average daily } \\
\text { output }\end{array}$} & \multirow{2}{*}{$\begin{array}{c}\text { Average } \\
\text { daily } \\
\text { balance }\end{array}$} \\
\hline & & Urine & Stool & & Urine & Stool & \\
\hline 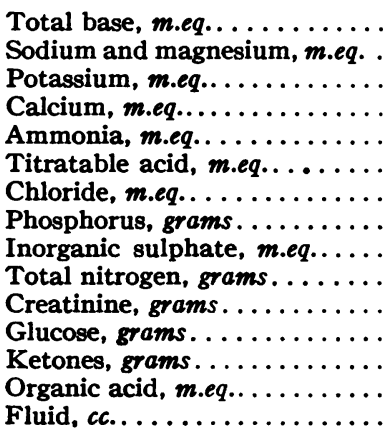 & $\begin{array}{c}406.8 \\
5.96 \\
63.2\end{array}$ & \begin{tabular}{|c|}
626.1 \\
332.0 \\
246.7 \\
47.4 \\
142.2 \\
129.8 \\
338.2 \\
3.96 \\
184.2 \\
53.3 \\
8.46 \\
0 \\
0.36 \\
181.2 \\
6375.
\end{tabular} & $\begin{array}{r}160.8 \\
29.6 \\
12.4 \\
119.2\end{array}$ & $\begin{array}{r}247.2 \\
117.4 \\
76.5 \\
53.3 \\
\\
101.7 \\
1.49 \\
15.8\end{array}$ & \begin{tabular}{|c|}
156.5 \\
83.0 \\
61.7 \\
11.9 \\
35.6 \\
32.5 \\
84.6 \\
0.99 \\
46.1 \\
13.3 \\
2.12 \\
0 \\
0.09 \\
45.3 \\
1594.
\end{tabular} & $\begin{array}{r}40.2 \\
7.4 \\
3.1 \\
29.8\end{array}$ & $\begin{array}{r}+50.5 \\
+27.0 \\
+11.7 \\
+11.6 \\
\\
+17.0 \\
+0.19 \\
+1.9\end{array}$ \\
\hline
\end{tabular}

the excretion of the other inorganic bases in the urine. Urinary ammonia excretion dropped slowly, reaching normal levels on the third day of the period which was also the first day in which ketone excretion was negligible.

Summarizing the first recovery period which was the more striking of the two, one finds an extraordinary retention of water and of the base fraction, $\mathrm{Na}+\mathrm{Mg}$ and of $\mathrm{Cl}$ in the first two days, with a somewhat less 
noteworthy retention of $\mathrm{K}$ and $\mathrm{P}$ during the same forty-eight hours. Nitrogen equilibrium was reestablished without significant evidence of tissue restoration as was true also of the patient T. M. Ammonia excretion dropped slowly, reaching the level of the foreperiod on the fourth day.

Recovery period II. This period of four days showed little of significance. Most of the urinary constituents had returned practically to foreperiod levels, weight remained essentially constant, and moderate nitrogen retention (+1.9 gram daily) took place. As compared with the foreperiod there was relatively greater retention of total inorganic base, more noticeable for the electrolytes $\mathrm{K}$ and $\mathrm{Ca}$ than for the base fraction $\mathrm{Na}+\mathrm{Mg}$. The average daily urine volume was $1594 \mathrm{cc}$. as compared with $1536 \mathrm{cc}$. in the foreperiod. The daily averages for $\mathrm{NH}_{3}$ excretion were: foreperiod, 33.7 m.eq. and recovery period II, 35.6 m.eq.

Anabysis of the balance study. Calculations have been made from the analytical data obtained in this patient, concerning the total electrolyte and water balances in the "acidosis" and recovery periods on the assumption of constant loss of these substances through the skin (Table 8). As in the case of the patient T. M., a great discrepancy was found between the calculated insensible perspiration (i.e., positive water balance) and the actual change in weight. In this case, the patient showed a net loss of $1.1 \mathrm{kgm}$. in body weight, whereas the fluid loss calculated from the above assumption would have been about 3.7 liters. The calculations, assuming constant skin loss, when applied to the electrolytes show closer agreement with the observed results, as was also true of the patient T. M.

Blood changes in the period of insulin withdrawal. The blood serum in this case (Table 9) showed no significant deviations from normal in the foreperiod. The two studies were in close agreement, establishing an excellent base line for comparison with the two determinations made in the "acidosis" period. The latter were so timed that the first set of analyses done after three days of insulin withdrawal showed only the effect of the initial loss of electrolytes and water before ketosis appeared, whereas the second specimen, taken on the last day of the "acidosis" period included the effects of mild ketosis. The hyperglycemia in this case exceeded that found in the patient T. M. and the ketonemia was much less marked; a maximum of 0.18 gram per liter for W. O'C. as compared with 1.13 gram for $T$. $M$. The serum $\mathrm{pH}$ was amazingly constant and no acidosis, either compensated or uncompensated, appeared. In fact, the $\mathrm{pH}$ at the time of maximal ketonemia was the highest observed result. The $\mathrm{CO}_{2}$ dissociation curve remained exactly at the same level, within the limits of error of the method, throughout the experiment.

Following the loss of body water and electrolytes in the first three days of the period of insulin withdrawal, the blood serum showed alterations similar to those pointed out by the authors (10) (11) (12) (13) in studies of 
ATCHLEY, LOEB, RICHARDS, BENEDICT AND DRISCOLL

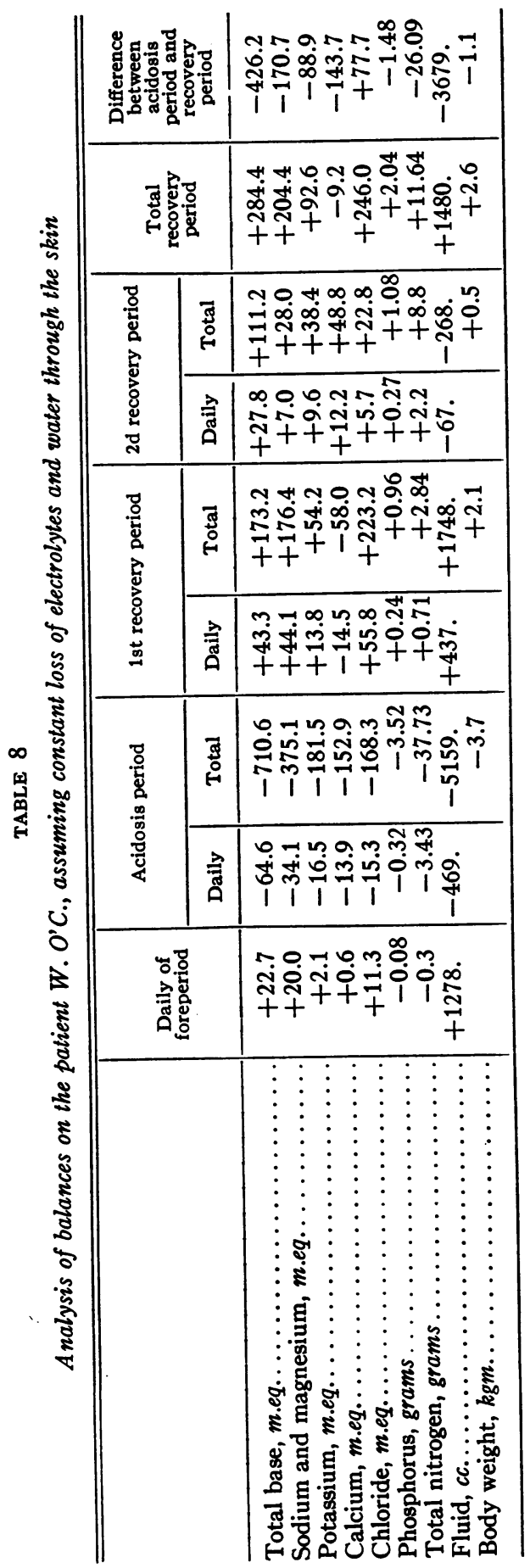




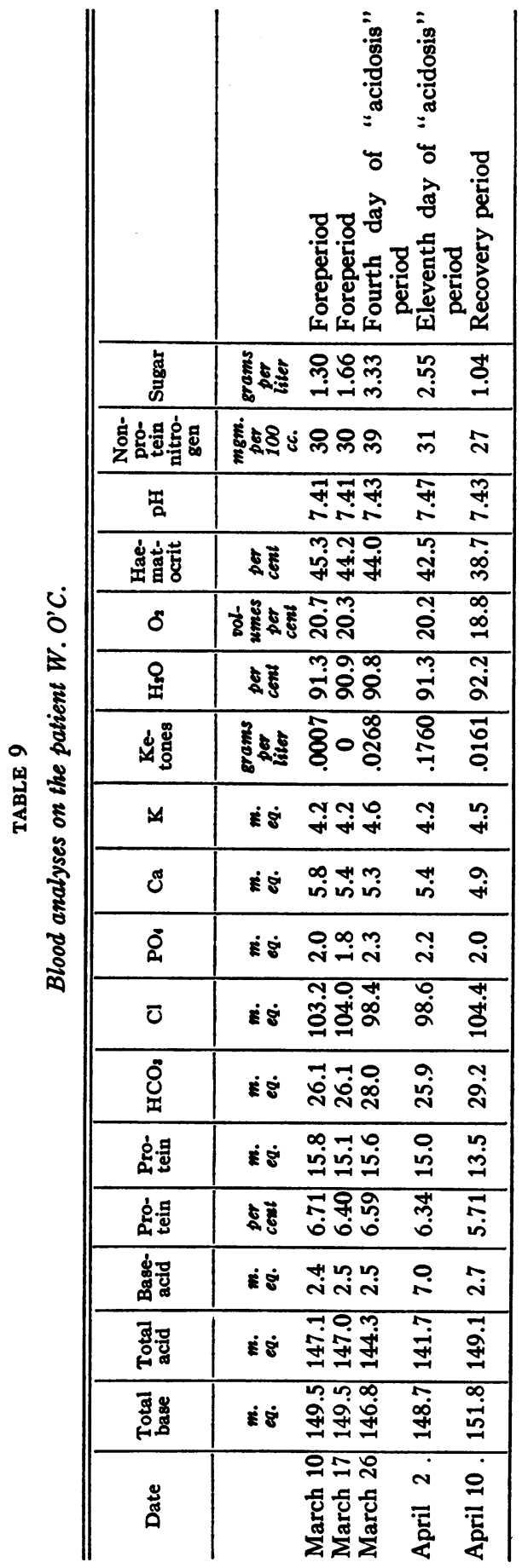


diuresis from various causes. The results in this patient were quantitatively not large, but are qualitatively similar and include (1) decrease in $\mathrm{Cl}$ (104.0 m.eq. to 98.4 m.eq.), (2) increase in bicarbonate (26.1 m.eq. to 28.0 m.eq.) which, however, is less marked. Accompanying this loss of chloride is a smaller loss of total base (149.5 m.eq. to 146.8 m.eq.) and no noteworthy change in serum water as indicated by relatively constant total solids, hematocrit and serum protein per cent. Sodium and chloride apparently left the blood serum without simultaneous loss of serum water although the rest of the body fluids lost large quantities of water, as evidenced both in urinary excretion and weight loss $(2.8 \mathrm{kgm}$.). It is interesting to note that the excess loss of $\mathrm{K}$ and base fraction $\mathrm{Na}+\mathrm{Mg}$ in the urine (over foreperiod levels) in the first three days of the "acidosis" period was 340 m.eq. in contrast to a loss of only $208 \mathrm{~m}$.eq. of $\mathrm{Cl}$ in the same period of time. Although inorganic base loss through the kidneys was much greater, the serum concentration of chloride decreased about twice as many m.eq. as did the concentration of inorganic base.

The mild ketosis which finally developed in this patient had little effect on the electrolyte pattern of the serum. There was a recognizable increase in the undetermined acid (B-A) probably representing, in main, the appearance of ionized ketones. However, it is surprising to observe the great discrepancy between the quantity of ketones found in the serum of the patient W. O'C. and the amount present in that of T. M. as compared with the undetermined acid fractions in the two instances. The undetermined acid in T. M. was 8.7 m.eq. with 0.86 gram per liter of ketones, whereas in the case of W. O'C. it was 7.0 m.eq. with a concentration of only 0.18 gram per liter of ketones. It is unlikely that the decrease in serum $\mathrm{pH}$ occurring in the patient $\mathrm{T}$. M. could account for a discrepancy of this magnitude in B-A, and the possibility of technical errors in the total base method must always be considered.

At the end of the "acidosis" period the total base of the serum had returned practically to the level of the foreperiod but chloride concentration showed no corresponding increase. It is noteworthy that although the total "acidosis" period showed (assuming constant skin loss) a net loss of 375.1 m.eq. of the base fraction $\mathrm{Na}+\mathrm{Mg}$ (Table 8), the chloride loss was only 168.3 m.eq. The base fraction $\mathrm{Na}+\mathrm{Mg}$ of the serum decreased only 0.8 m.eq. during the period, whereas the simultaneous decrease of serum chloride concentration was $5.4 \mathrm{~m} . e q$. It is equally difficult to explain the lack of relationship between the greatly increased loss of body water during the "acidosis" period and the coincident dilution of the blood serum over the same period of time as evidenced in decreased serum protein per cent, hematocrit and total solids. This forms a striking contrast to the changes accompanying the development of severe acidosis in the patient T. M.

Blood removed at the end of the recovery period was similar to the 
two foreperiod controls. Further dilution of serum beyond that of the acidosis period had occurred and slightly increased levels of total base and bicarbonate were observed.

\section{DISCUSSION}

This study of the quantitative changes resulting from the abrupt withdrawal of insulin in patients suffering from diabetes of varying degrees of severity has yielded considerable data concerning some of the disturbances in electrolyte physiology occurring during the development of diabetic acidosis. In one of the patients presented above, W. O'C., the withdrawal of insulin was associated with the development of marked and persistent glycosuria and very mild ketosis, but without the development of acidosis. In the other patient, T. M., severe acidosis developed within four days. In many respects the analytical data show striking similarities in the reactions of these two patients, and it has consequently been possible to segregate those changes associated with the development of severe glycosuria alone from those due to the combined effects of glycosuria and ketogenic acidosis.

It is important at this point to consider the possibility that insulin withdrawal by itself, without disturbances in carbohydrate metabolism, might be responsible for some of the changes which were observed. In a study which we have made of a mild diabetic patient who excreted only 23 grams of glucose on the fourth day after stopping his daily injections of 55 units of insulin, no significant changes in water or electrolyte metabolism occurred. This demonstrated that the deviations observed in the two patients reported in this paper were not due to the effect of insulin withdrawal, per se, but were dependent primarily upon the resulting disturbances in carbohydrate metabolism. The analytical data obtained in the study of this mild diabetic have not been presented because they were of only negative value.

Responses of water and electrobytes to disturbances of carbohydrate metabolism. Polyuria has always been recognized as a concomitant phenomenon of marked glycosuria. It is apparent from work reported in this paper that sudden interference with carbohydrate metabolism not only causes a greatly increased water excretion, but also brings about an equally pronounced excretion of the electrolytes normally present in intraand extracellular fluids. The abrupt return to normal carbohydrate metabolism, as a result of insulin therapy, is accompanied by the reverse effect, namely, marked retention of water and electrolytes, particularly $\mathrm{Na}, \mathrm{K}$ and $\mathrm{Cl}$. This movement of water and electrolytes is, in most respects, similar to that observed in fasting infants (1), in $\mathrm{CaCl}_{2}$ and $\mathrm{NH}_{4} \mathrm{Cl}$ acidosis (2) (3), in cardiac diuresis (12) and in spontaneous diuresis in nutritional edema (13). Furthermore, as was pointed out in the preceding section, the effect of these changes in electrolyte and water excre- 
tion on the electrolyte pattern of the blood serum is qualitatively similar to that observed in diuresis in cardiac and nutritional edema. Thus it is apparent that these changes comprise a general type of response not necessarily dependent upon disturbances of carbohydrate metabolism.

Alterations in water balance associated with the sudden breakdown of normal carbohydrate metabolism have been ascribed to a hypothetical relationship between water and glycogen storage. This point of view has been challenged recently by Bridge and Bridges (14) who have been unable to confirm the original observations upon which this hypothesis was founded. The changes in water and electrolyte balances described in our studies are of an order of magnitude far greater than could be explained on this basis. Even on the unjustified assumption of complete deglycogenation of the patients and on the further assumption that four grams of water are lost with each gram of glycogen, it would not be possible to account for more than half of the observed water loss. Furthermore, an analysis of the electrolyte excretion showed an output of sodium sufficiently great to make it certain that the amount of extracellular water lost from the body was no less striking than that of water lost from within the cells. Since glycogen storage is entirely an intracellular phenomenon, it may be inferred that all water released by glycogen breakdown should have the electrolyte structure of intracellular fluid.

These facts might, however, be harmonized in the following manner: Let it be supposed that with glycogen loss there occurs a considerable loss of intracellular fluid, and with the latter fluid, its proper content of potassium. It is well known that potassium salts exert a strong diuretic effect, both with respect to the extracellular and intracellular fluid. If, then, the endogenous potassium, released by glycogen breakdown, exerts a similar diuretic effect, this might account for the great excretion of water and electrolytes, both intra- and extracellular, which we have found to occur.

Responses of water and electrolytes to ketogenic acidosis. Odin (15) observed that the withdrawal of insulin from diabetic patients resulted in augmented excretion of inorganic base and that this was later followed by an increase in the rate of ammonia excretion. This author interpreted his results as indicating a mobilization of inorganic base dependent upon the formation of ketone acids. From the foregoing discussion and the analytical data presented in this paper, it becomes obvious that the initial loss of inorganic base in the acute diabetic state is not primarily dependent upon the development of ketosis but accompanies the sudden appearance of marked glycosuria. It may be recalled that in the patient, W. O'C., who developed an insignificant ketosis, the peak of base excretion and loss of body water appeared within the first forty-eight hours of insulin withdrawal and thereafter the rate of excretion fell to a lower level which was, however, higher than that of the foreperiod. In contrast to 
this chain of events, the patient T. M., who developed a severe and rapidly increasing ketosis, showed a secondary rise in the excretion of inorganic base surpassing the highest level reached with the initial disturbance of carbohydrate metabolism. It is thus apparent that the excretion of ketones in large amounts greatly augments the loss of sodium and potassium and water which accompanies the development of glycosuria, and that the loss of potassium was greater in relation to the loss of sodium in the patient who developed acidosis.

It is evident that such rapid loss of sodium and potassium, if continued, would soon bring about a depletion of base in the body sufficient to cause dehydration of the tissues, and also a decrease in blood volume with the state of shock as an end result. This point of view is confirmed by the well-defined concentration of the blood in the patient T. M. which occurred when the clinical and chemical manifestations of acidosis became acute.

Gamble et al. (1) in 1923 emphasized the general physiological association between the movement of water and inorganic base. The observations reported in this paper are in harmony with this rational physicochemical concept. When, however, one considers the behavior of the chloride ion, variations are encountered which do not lend themselves to interpretation. For example, in the patient W. O'C. the concentration of base in the blood serum decreased only 3 m.eq. upon insulin withdrawal, whereas the chloride concentration fell almost twice this amount. At the same time, the patient excreted far more sodium and potassium than he did chloride. This retention and apparent migration of chloride to the tissues is much greater than can be explained on the assumption of a shift from serum to tissue fluids resulting from a change in blood $\mathrm{pH}$ (the effect on the Donnan ratio was calculated according to the method of Van Slyke, Wu and McLean (16)). Furthermore, it is difficult to understand the fact that whereas both patients lost base approximately in proportion to the loss in body water, the loss of chloride was far less. Finally, it is perplexing that the patient T. M., who developed severe acidosis and had a far greater loss of base from the body than did the patient W. O'C., should have excreted actually, as well as relatively, less chloride upon the withdrawal of insulin.

As has been stated, Odin (15) demonstrated that following the withdrawal of insulin in diabetic patients there is a lag in the augmentation of ammonia excretion. This observation has been confirmed in our studies but no definite quantitative relationship to the development of ketosis can be established. For example, the patient T. M. showed a smaller increase in $\mathrm{NH}_{3}$ excretion with the appearance of 3.5 grams of ketone bodies in the urine than did the patient W. O'C. when he excreted 0.15 gram of ketones. Perhaps more striking than the lag in the augmentation of $\mathrm{NH}_{3}$ excretion is the delay in its return to normal levels after the 
readministration of insulin. In spite of the fact that ketonuria was essentially terminated in the patient T. M. within twenty-four hours after starting insulin, $\mathrm{NH}_{3}$ excretion did not return to the level of the foreperiod for four days. While the changes were quantitatively smaller in the case of patient $\mathrm{W}$. O'C., the fact remains that $\mathrm{NH}_{3}$ excretion was augmented for three days after insulin therapy was re-instituted. It may be stated in general that $\mathrm{NH}_{3}$ continues to be excreted in abnormally large amounts until most of the potassium and sodium lost from the body have been restored to the tissues and tissue spaces. That the added ammonia formation and its continued excretion at augmented levels is not determined by the $\mathrm{pH}$ of the blood is obvious.

Responses of nitrogen metabolism to disturbances in carbohydrate metabolism. Both patients, upon the appearance of severe glycosuria, showed an immediate rise in urinary nitrogen excretion which remained relatively constant at a level considerably above that of the foreperiod. This was not wholly dependent upon the severity of ketosis although the patient who developed acidosis showed a greater percentage increase in nitrogen loss than did the other patient. It is of interest that both patients returned to approximate nitrogen balance within forty-eight hours after insulin therapy was again started. While the restoration of water and electrolytes to the tissues was prompt and relatively complete, there was in the course of the nine days of the recovery period virtually no restoration of the nitrogen lost by the patient T. M. and only minimal storage in the patient W.O'C. in the course of eight days.

Implications referable to electrobyte balance studies in general. In the course of this work several observations were made that were not directly relevant to the problem of diabetic acidosis. As has been pointed out in the discussion above, particularly as regards chloride metabolism, it is obvious that one must be guarded in drawing conclusions concerning the total metabolism of an ion from the changes that take place in its concentration in the blood serum. It is quite possible for the serum level to be higher following a period of actual negative balance. In making such balance studies we, as well as others, have found that practically all the essential changes occur in the urinary constituents. Stool analyses contributed nothing to the knowledge of mechanisms by which the human body adjusts to the type of stress occurring in our patients.

It may be worth noting that the discrepancies in the behavior of the chloride ion described in this paper are no less striking than those brought out in similar electrolyte studies in other conditions (4).

The behavior of the calcium ion in these experiments as well as in balance studies on a normal subject reported elsewhere (5) and on two normal individuals, as yet unpublished, show certain similarities that do not seem to be related to the patient's disease or to his treatment. In all the individuals that we have employed (three normal and three diabetic) 
there has been a constant and increasing development of a negative calcium balance. If the patient were in equilibrium at the beginning, his balance became negative; if the balance were positive at first it became less so during the period of observation. Gamble, Ross and Tisdall (1) found a loss of $\mathrm{Ca}$ in their fasting infants and attributed it to the ketogenic acidosis occurring during starvation. It seems probable in view of our findings, that part of the loss of calcium in our studies was due to decalcification of the bony structures dependent upon the relative inactivity of the experimental regime. However, in the case of T. M. during his severe acidosis, there was a temporary increase in urinary calcium that was far greater than any alteration of calcium excretion in those subjects who had no acidosis.

We have repeatedly called attention to the difficulty of interpreting electrolyte balance studies in the absence of data on skin excretion. To ignore skin loss is obviously absurd and the assumption of constant skin excretion has no sound support. Moreover, there is no reason for believing that the distribution of base in sweat is similar to that of the blood or urine. Swanson and Iob $^{8}$ have shown that infants on a diet of cow's milk excrete through the skin more base than chlorine and much more $\mathrm{K}$ than Na. Water excretion through the skin changed tremendously (cf. above) under the conditions of our experiments and probably not in any consistent quantitative relationship to the mineral loss by the same route. Hence, detailed inferences as to cell or tissue space storage of electrolytes and water derived from comparisons of water and food intake with urine and stool are not satisfactory at present.

The extreme variations in water excretion through the skin which occurred in our diabetic subjects indicate that insensible perspiration is definitely dependent, in part at least, upon the water requirements of the tissues. For this reason it seems clear that the role of water equilibrium must be an important consideration in the use of the insensible perspiration as an index of total metabolism.

\section{CONCLUSIONS}

1. The effects of the withdrawal and reestablishment of insulin therapy in two diabetic subjects have been studied intensively by means of relatively complete electrolyte balances.

2. In the analysis of these experiments it has been possible to segregate the disturbances due to extensive alteration of carbohydrate metabolism alone, from those dependent upon ketogenic acidosis.

3. The effects of insulin withdrawal upon the two subjects, one of whom developed a ketogenic acidosis, and the other a glycosuria with minimal ketosis, may be summarized as follows:

${ }^{8}$ Personal communication. 
(a) During the first forty-eight hours, accompanying the initial glycosuria, and before the development of acidosis, both patients showed essentially the same response, namely a loss of both intra- and extracellular body water, together with their constituent electrolytes.

(b) In the patient with simple glycosuria, during the days succeeding withdrawal of insulin, the water and electrolyte excretion continued at a level above that of the foreperiod, though less than during the first fortyeight hours. Glucose, water and electrolyte excretion proceeded at an approximately constant rate, at this new level.

(c) The other patient (T. M.) also began on his second day of insulin withdrawal, to decrease his water and electrolyte output. Then, however, with the progressive development of ketogenic acidosis, there occurred a second rise in water and electrolyte excretion. This was qualitatively similar to that of the first two days. It continued progressively until terminated by restoration of insulin therapy.

(d) During recovery, following readministration of insulin, the responses of both patients were the same, there was retention of intracellular and extracellular water and their constituent electrolytes. Glycosuria and ketonuria subsided promptly.

(e) In both patients the level of ammonia excretion remained above that of the foreperiod for three to four days after the termination of ketosis.

$(f)$ In both patients there appeared to be a decrease in water loss through the skin during the "acidosis" and recovery periods as compared with the foreperiod.

\section{BIBLIOGRAPHY}

1. Gamble, J. L., Ross, G. S., and Tisdall, F. F., J. Biol. Chem., 1923, lvii, 633. The Metabolism of Fixed Base during Fasting.

2. Gamble, J. L., Blackfan, K. D., and Hamilton, B., J. Clin. Invest., 1925, i, 359. A Study of the Diuretic Action of Acid Producing Salts.

3. Fфlling, A., Acta med. Skandinav., 1929, lxxi, 221. On the Mechanism of the Ammonium Chloride Acidosis.

4. Atchley, Dana W., and Benedict, Ethel M., J. Biol. Chem., 1927, lxxiii, 1. The Distribution of Electrolytes in Dogs following Ligation of both Ureters.

5. Loeb, Robert F., Atchley, Dana W., Richards, Dickinson, W., Jr., Benedict, Ethel M., and Driscoll, Mary E., J. Clin. Invest., 1932, xi, 621: On the Mechanism of Nephrotic Edema.

6. Van Slyke, D. D., and Sendroy, J., Jr., J. Biol. Chem., 1928, lxxix, 781. Studies of Gas and Electrolyte Equilibria in Blood. XV. Line Charts for Graphic Calculations by the Henderson-Hasselbalch Equation, and for Calculating Plasma Carbon Dioxide Content from Whole Blood Content.

7. Austin, J. H., Cullen, G. E., Hastings, A. B., McLean, F. C., Peters, J. P., and Van Slyke, D. D., J. Biol. Chem., 1922, liv, 121. Studies of Gas and Electrolyte Equilibria in Blood. I. Technique for Collection and Analysis of Blood and for its Saturation with Gas Mixtures of Known Composition. 
8. Richards, D. W., Jr., and Strauss, M. L., J. Clin. Invest., 1927, iv, 105. Oxy-hemoglobin Dissociation Curves of Whole Blood in Anemia.

9. Richards, D. W., Jr., and Strauss, M. L., J. Clin. Invest., 1930, ix, 475. $\mathrm{CO}_{2}$ and $\mathrm{O}_{2}$ Tensions of the Mixed Venous Blood of Man at Rest.

10. Atchley, Dana W., Loeb, Robert F., Benedict, Ethel M., and Palmer, Walter W., Arch. Int. Med., 1923, xxxi, 616. Physical and Chemical Studies of Human Blood Serum. III. A Study of Miscellaneous Disease Conditions.

11. Atchley, Dana W., and Benedict, Ethel M., J. Clin. Invest., 1930, ix, 265. Serum Electrolyte Studies in Normal and Pathological Conditions: Pneumonia, Renal Edema, Cardiac Edema, Uremic and Diabetic Acidosis.

12. Barach, A. L., and Richards, D. W., Jr., Arch. Int. Med., 1931, xlviii, 325. Effects of Treatment with Oxygen in Cardiac Failure.

13. Atchley, Dana W., Loeb, Robert F., Benedict, Ethel M., J. A. M. A., 1923, lxxx, 1643. Physicochemical Studies of Calcium Chlorid Diuresis.

14. Bridge, E. M., and Bridges, E. M., J. Biol. Chem., 1931, xciii, 181. The Relation of Glycogen to Water Storage in the Liver.

15. Odin, Martin, Acta. med. Skandinav., 1928, lxix, 254. Die Ursache des raschen Eintretens von Koma auf plötzliches Abbrechen der Insulinzufuhr bei insulinbehandelten Diabetesfällen.

16. Van Slyke, D. D., Wu, H., and McLean, F. C., J. Biol. Chem., 1923, lvi, 765. Studies of Gas and Electrolyte Equilibria in the Blood. V. Factors Controlling the Electrolyte and Water Distribution in the Blood. 